\title{
Synthesis of new ionic liquid-grafted metal-oxo nanoclusters - Design of nanostructured hybrid organic-inorganic polymer networks
}

\author{
Houssém Chabane $^{\mathrm{a}}$, Sébastien Livi ${ }^{\mathrm{a}, *}$, Xavier P. Morelle ${ }^{\mathrm{a}}$, Rodolphe Sonnier ${ }^{\mathrm{b}}$, LoïcDumazert ${ }^{\mathrm{a}}$, \\ Jannick Duchet-Rumeau ${ }^{a}$, Jean-François Gérard ${ }^{\text {a, }}{ }^{* * *}$
}

${ }^{a}$ Université de Lyon - INSA Lyon, UMR CNRS 5223, IMP Ingénierie des Matériaux Polymères, F-69621, Villeurbanne, France

${ }^{\mathrm{b}}$ IMT Mines-Alès, Centre des Matériaux (C2MA) - Pôle Matériaux Polymères Avancés, 6 Avenue de Clavières, 30319, Ales Cedex, France

\begin{abstract}
A B S T R A C T
Designing innovative multi-functional thermoset polymers represents a major challenge in materials science. In this work, two novel polyhedral imidazolium ionic liquid supported on oligomeric silsesquioxane nanocages having chloride $\left(\mathrm{Cl}^{-}\right)$and bistrifluoromethanesulfonimidate $\left(\mathrm{NTf}_{2}\right)$ counter anions have been synthesized. These ionic nano-objects were used to nanostructure a model epoxy network. Hence, networks displaying a homogeneous nanoscale morphology were obtained by introducing $5 \mathrm{wt} \%$ of such organic-inorganic (O/I) silicon-oxo clusters functionalized with ionic liquids. The obtained ionic hybrid O/I epoxy-amine networks display an excellent thermal stability $\left(>400{ }^{\circ} \mathrm{C}\right)$ compared to their neat counterparts, as well as a pronounced hydrophobic character $\left(23 \mathrm{~mJ} \mathrm{~m}^{-2}\right)$ and good mechanical performances. Moreover, these $\mathrm{O} / \mathrm{I}$ nanostructured networks demonstrate an improved fire resistance according to pyrolysis-combustion flow calorimetry (PCFC) and cone calorimetry analyses. In fact, the use of low amounts of imidazolium ionic liquid-modified polyhedral oligomeric silsesquioxanes induce a significant decrease of heat release rate (about 55\%), as well as a retardation of the ignition time (close to 29\%) compared to the neat epoxy-amine network.
\end{abstract}

Keywords:

Ionic liquid

Polyhedral oligomeric silsesquioxane (POSS $($ )

Epoxy network

Organic-inorganic nanomaterials

Fire resistance

\section{Introduction}

Due to their interesting physical properties including optical transparency, high electrical resistance and thermal insulation capabilities in parallel with good thermo-mechanical properties and dimensional stability, epoxy networks represent an important class of thermoset polymers, widely used in applications going from adhesives, paints and coatings, insulating layers in electronics to matrices for composites used in automotive and aerospace industries [1,2]. However, the highly-crosslinked nature of such thermoset polymers leads to a brittle behavior, i.e. materials with a poor resistance to crack propagation when subjected to mechanical loading, as well as thermal changes $[3,4]$. More particularly, the fire resistance of epoxy polymers based on diglycidyl ether of bisphenol A (DGEBA) is a major drawback restricting their use for applications requiring high-standard fire safety $[5,6]$.

In order to overcome these limitations, various routes have been investigated over the years. Regarding improvement of toughness, the most common approach consists in introducing a dispersed ductile phase within the epoxy network using thermally stable and high- $\mathrm{T} g$ thermoplastic polymers (TP) (such as polyetherimide (PEI), polyethersulfone (PES), polyphenylene ether (PPE)) or reactive elastomers (such as functionalized poly(butadiene-co-acrylonitrile) rubbers (CTBN, ETBN)) through a reaction-induced phase separation occurring during curing [7-9]. Nevertheless, the incorporation of such compounds usually results in a significant reduction of stiffness (i.e. Young modulus) and in some cases to a lower glass transition temperature due to non-perfect microphase separation, in addition to an important increase of flammability.

Regarding fire resistance, two main approaches have been studied to obtain fire resistant (FR) epoxy polymers: the first consists in introducing halogenated fire-retardant compounds in a conventional epoxy polymer, and the second involves modifying the chemical structure of the epoxy prepolymer (e.g. brominated epoxy resins). Nowadays, such compounds tend to be subjected to drastic regulations, in terms of quantity and field of use, due to environmental and health concerns regulated by new European directives such as REACH [10]. Research

\footnotetext{
* Corresponding author.

$* *$ Corresponding author.

E-mail addresses: sebastien.livi@insa-lyon.fr (S. Livi), jean-francois.gerard@insa-lyon.fr (J.-F. Gérard).
} 
groups have thus been looking for alternatives, among which phosphorus-based compounds, phosphorus-modified resin backbones and/or hardeners have attracted great interest [11]. In many cases though, those compounds need to be used in high concentration, which can sometimes bring detrimental changes to other material properties such as mechanical properties [12]. More recently, others improvement routes reported in the literature have turned towards the introduction of nanoparticles, such as silicate clays or carbon nanotubes, in order to combine the effects of reinforcement of filled polymers and the fire resistance conveyed by nanocomposites [13,14]. Nonetheless, such synergetic effect can only be obtained if the nanoparticles are well dispersed, which remains challenging and rather difficult for most polymers. Referring to recent studies, a promising path seems to be the introduction of polyhedral oligomeric silsesquioxane (POSS $\left.{ }^{\circledR}\right)$, known for their fire-retardant properties, into epoxy networks $[13,15,16]$.

Polyhedral Oligomeric Silsesquioxanes, now called POSS ${ }^{\circledR}$, refer to all the molecular structures with the empirical formula $\left(\mathrm{RSiO}_{1.5}\right)_{\mathrm{n}}$, where $\mathrm{R}$ is a hydrogen atom or an organofunctional derivative of alkyl, alkylene aryl, or arylene groups. The terme "silesqui" refers to the ratio of the silicon to oxygen atoms, i.e. Si:O = 1:1.5 [17]. POSS ${ }^{\circledR}$ are incompletely oxidized silicate compound compared to $\mathrm{SiO}_{2}$ with a cage structure having different numbers of silicon atoms. The sizes of these molecular objects range from 1 to $3 \mathrm{~nm}$ [17]. The most common POSS ${ }^{\circledR}$ have a cubic $\mathrm{T}_{8}$ cages with a general formula $\mathrm{R}_{8} \mathrm{Si}_{8} \mathrm{O}_{12}$ [17]. Numerous papers reported studies on hybrid organic-inorganic (O/I) nanomaterials based on epoxy matrices modified by POSS ${ }^{\circledR}$. For example, Laine et al. [18-22] and Matejka et al. [23] described the effect of a series of functionalized and non-functionalized POSS ${ }^{\circledR}$ with various $R$ groups such as aminophenyl, dimethylsiloxypropylglycidyl ether, epoxy, or alkyl groups (isobutyl, methyl, and ethyl) on the dynamic mechanical properties, fracture toughness, and thermal stability of the resulting $\mathrm{O} / \mathrm{I}$ epoxy nanomaterials. The incorporation of POSS ${ }$ in epoxy networks can result both in an increase [24-26] or a decrease [27, 28] of mechanical properties, i.e. stiffness and toughness. In fact, POSS ${ }^{\circledR}$ nano-objects usually tend to easily aggregate leading to the formation of inorganic-rich domains within the epoxy networks [23]. Therefore, tailoring the balance of interactions between the polymer medium, the

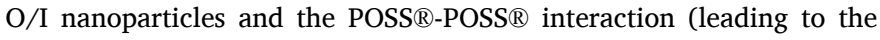
formation of microsize aggregates) is a key issue for designing proper inorganic-rich nanostructures required for enhancements of mechanical properties [29-36] in addition to fire resistance. Recently, several groups reported significant advantages of using ionic liquids (ILs) as dispersing agents for epoxy matrices reinforced with silica nanoparticles $[37,38]$. These authors have shown that the introduction of ILs based on imidazolium-based cations was a promising strategy for tailoring nanocomposite morphology at the nanoscale $[37,38]$.

ILs are organic salts with a melting temperature lower than $100{ }^{\circ} \mathrm{C}$ that were recently proposed to be combined with epoxy curing chemistry to prepare novel functional materials [39-41]. These ionic compounds have interesting properties such as high thermal and chemical stabilities, a low saturation vapor pressure, non-flammability and dispersant capabilities, catalytic activity, and a high ionic conductivity, which makes them very attractive not only for the present purpose but for polymer science in general [42-51]. Hence, ILs have now emerged in many polymer-based applications. For instance, in epoxy chemistry, ILs can act as catalysts and/or curing agents promoting an anionic polymerization of the epoxy prepolymer leading to significant improvements of the thermo-mechanical properties of the resulting networks compared to conventional epoxy networks [52-54]. POSS $₫$ and ionic liquids have also been recently combined to prepare new hybrid compounds by synthesizing IL-grafted POSS ${ }^{\circledR}$. The corresponding ionic O/I nanoclusters have been used as electrolytes for electrochemical devices [55] or to enhance the proton conductivity of membranes [56] but to the best of our knowledge no authors have proposed to introduce such nano-objects in an epoxy network. In a previous study, we reported that the connection of ion pairs to POSS ${ }^{\circledR}$ nanoclusters, i.e. from grafting an ionic liquid of POSS $₫$ bearing different organic ligands (isobutyl or phenyl), can significantly improve the POSS $₫ /$ epoxy matrix interactions and promote the formation of well-dispersed POSS ${ }^{\circledR}$ nanodomains [57]. From these first promising results, we investigate here ionic liquid grafted on phenyl POSS ${ }^{\circ}$, denoted as IL-g-POSS ${ }^{\mathrm{Ph}}$ with two different anions $\left(\mathrm{Cl}^{-}\right.$and $\left.\mathrm{NTf}_{2}\right)$ considered as hybrid $\mathrm{O} / \mathrm{I}$ nano-objects for designing nanostructured and multifunctional epoxy-amine networks. The anionic exchange of $\mathrm{Cl}^{-}$to $\mathrm{NTf}_{2}$ was studied here because the later one is known to give materials with better thermal stability and higher $\mathrm{T}_{\mathrm{g}}[54,58]$. The present study unfolds as following: first, the influence of non-modified POSS $\AA^{\mathrm{Ph}}\left(\mathrm{POSS} \AA^{\mathrm{Ph}}\right.$-triol) and IL-g-POSS $\AA^{\mathrm{Ph}}$ on the polymerization of the epoxy prepolymer is described. Then, the morphologies of the two types of POSS ${ }^{\mathrm{Ph}}$ modified epoxy networks are compared as well as their physical and mechanical properties. Eventually, the potential for fire retardancy of IL-grafted POSS ${ }^{\mathrm{Ph}}{ }^{\mathrm{Ph}}$ modified epoxies is more specifically investigated.

\section{Materials and characterization methods}

\subsection{Materials}

1-methylimidazole (99\%), 3- chloropropyltrimethoxysilane (97\%), isophoronediamine (IPD), and lithium bistrifluoromethanesulfonimidate $\left(\operatorname{LiNTf}_{2}\right)$ considered for anionic exchange procedure, the solvents (diethyl ether, ethanol, chloroform, and dichloromethane) were purchased from Sigma Aldrich and used as received. Epoxy prepolymer based on diglycidyl ether of bisphenol A (DGEBA) (EPON 828 from Hexion) and heptaphenyl-trisilanol POSS $₫$, denoted POSS ${ }^{\mathrm{Ph}}$-triol, from Hybrid Plastics were used as received. All the chemical structures of non-grafted and IL-grafted POSS ${ }^{\circledR}$ used and synthesized are summarized in Table 1.

\subsection{Anionic exchange procedure of polyhedral oligomeric silsesquioxane $\left(\mathrm{POSS} \mathbb{R}^{\mathrm{Ph}}\right.$ ) (chloride $\mathrm{Cl}^{-}$vs. bistriflimidate $\mathrm{NTf} \mathrm{f}_{2}$ )}

The anion exchange reaction of $\mathrm{Cl}^{-}$by $\mathrm{NTf}_{2}$ following the same procedure as in Refs. [59,60], i.e. an equimolar amount (2.83 g, 9.86 mmol) of LiNTf $_{2}$ was added to a solution of IL.Cl-g-POSS ${ }^{P h}(10 \mathrm{~g}, 8.96$ $\mathrm{mmol})$ in dried ethanol $(150 \mathrm{~mL})$ and the mixture was left under stirring at room temperature for $24 \mathrm{~h}$. The resulting white powder was solubilized in dichloromethane $\left(\mathrm{CH}_{2} \mathrm{Cl}_{2}\right)$, dried, filtered, and washed several times with water. The obtained product, i.e. $\mathrm{IL}_{\text {. }} \mathrm{NTf}_{2}-\mathrm{g}-\mathrm{POSS}{ }^{\mathrm{Ph}}$ was then dried at $80{ }^{\circ} \mathrm{C}$ for $48 \mathrm{~h}$. The anionic exchange was checked by complexometric chloride titration considering silver nitrate $\left(\mathrm{AgNO}_{3}\right)$. The structure of the resulting salts was confirmed by ${ }^{13} \mathrm{C}$ NMR and FT-IR spectroscopies as illustrated in Fig. S2 and S3 of the Supporting Information (SI).

\subsection{Epoxy network synthesis}

Epoxy prepolymer (DGEBA) and isophorone diamine (IPD) were used as co-mononers considering a stoichiometric ratio, i.e. amino hydrogen-to-epoxy group equal to one.

5 wt $\%$ of POSS $\AA^{\mathrm{Ph}}$-triol or IL-g-POSS ${ }^{\mathrm{Ph}}{ }^{\mathrm{Ph}}$, either with chloride $\left(\mathrm{Cl}^{-}\right)$ or bis(trifluoromethane)sulfonimide $\left(\mathrm{NTf}_{2}\right)$ as counter anions, were incorporated in the epoxy reactive systems. DGEBA and POSS $\AA^{\mathrm{Ph}}$-triol or IL-g-POSS $\AA^{\mathrm{Ph}}$ were mixed at $120^{\circ} \mathrm{C}$ in order to obtain a homogeneous and transparent solution before adding the isophorone diamine used as hardener. Next, the mixture was degassed and then poured into a mold. As a last step, the reactive systems were polymerized for $1 \mathrm{~h}$ at $140{ }^{\circ} \mathrm{C}$ and post-cured $8 \mathrm{~h}$ at $190{ }^{\circ} \mathrm{C}$ [61-63] while the epoxy-amine networks with IL-g-POSS $\AA^{\mathrm{Ph}}$ were post-cured a second time at $230{ }^{\circ} \mathrm{C}$ for an additional $3 \mathrm{~h}$ in order to ensure a complete polymerization. 
Table 1

Chemical structures of non-grafted and IL-grafted POSS $®$.

\begin{tabular}{|c|c|c|}
\hline Name & Chemical formula & Characteristics \\
\hline Heptaphenyl-trisilanol POSS $®\left(\right.$ POSS ${ }^{\mathbf{P h}}$-triol) & & $\begin{array}{l}\mathrm{M}=931.34 \mathrm{~g} \mathrm{~mol}^{-1} \\
\mathrm{~T}_{\mathrm{m} 1}=217^{\circ} \mathrm{C}^{\mathrm{a}} \\
\mathrm{T}_{\mathrm{m} 2}=230^{\circ} \mathrm{C}^{\mathrm{a}} \\
\mathrm{T}_{\mathrm{d}}=617^{\circ} \mathrm{C}^{\mathrm{b}}\end{array}$ \\
\hline $\begin{array}{l}\text { 1-methyl-3-propyl heptaphenyl octasilesquioxane imidazolium chloride (IL.Cl-g- } \\
\text { POSS } \AA^{\mathbf{P h}} \text { ) }\end{array}$ & & $\begin{array}{l}\text { Prepared following the procedure reported in } \\
{[57]} \\
\mathrm{M}=1116.04 \mathrm{~g} \mathrm{~mol}^{-1}, \\
\mathrm{~T}_{\mathrm{m} 1}=134{ }^{\circ} \mathrm{C}^{\mathrm{a}}, \\
\mathrm{T}_{\mathrm{m} 2}=168^{\circ} \mathrm{C}^{\mathrm{a}}, \\
\mathrm{T}_{\mathrm{d}}=543^{\circ} \mathrm{C}^{\mathrm{b}}\end{array}$ \\
\hline $\begin{array}{l}\text { 1-methyl-3-propyl heptaphenyl octasilesquioxane imidazolium } \\
\text { bis(trifluoromethane)sulfonimide } \\
\text { (IL.NTf }_{2} \text {-g-POSS } \AA^{\text {Ph }} \text { ) }\end{array}$ & & $\begin{array}{l}\mathrm{M}=1360.73 \mathrm{~g} \mathrm{~mol}^{-1} \\
\mathrm{~T}_{\mathrm{m} 1}=135^{\circ} \mathrm{C}^{\mathrm{a}} \\
\mathrm{T}_{\mathrm{m} 2}=158^{\circ} \mathrm{C}^{\mathrm{a}} \\
\mathrm{T}_{\mathrm{d}}=534^{\circ} \mathrm{C}^{\mathrm{b}}\end{array}$ \\
\hline
\end{tabular}

${ }^{\text {a }} \mathrm{T}_{\mathrm{m}}$ : Melting temperature.

b $\mathrm{T}_{\mathrm{d}}$ : Degradation temperature determined at the maximum of the first derivative of the weight loss as function of the temperature (see Fig. S1 in the SI).

\subsection{Sol-gel analysis of hybrid $\mathrm{O} / \mathrm{I}$ networks}

A complete characterization of the POSS ${ }^{\circledR}{ }^{\mathrm{Ph}}$-modified networks is required to determine the amount of POSS ${ }^{\mathrm{Ph}}$ nanocages bonded to the networks. Thus, the POSS $\AA^{\mathrm{Ph}}$-modified networks were submitted to THF extraction at $60^{\circ} \mathrm{C}$ for $24 \mathrm{~h}$ to determine a fraction of the soluble portion containing unbounded POSS $\AA^{\mathrm{Ph}}$. The soluble fraction, denoted as $w_{s}$, was evaluated from the weight of the dried specimen, $m_{d r y}$, and the one of the specimen after extraction, $m_{\text {dry-ext }}$.

\subsection{Characterization}

Fourier Transform Infrared Spectroscopy (FTIR): FT-IR spectra were recorded using a Thermo-Scientific Nicolet iS10 Spectrometer from 4000 to $500 \mathrm{~cm}^{-1}$.

${ }^{13} \mathrm{C}$-NMR spectra were recorded using a Bruker Avance II $400 \mathrm{MHz}$ spectrometer at room temperature with appropriate deuterated solvent (acetone- $\mathrm{d}_{6}$ ).

Transmission electron microscopy (TEM) was carried out at the Technical Center of Micro-Structures (University of Lyon) using a Phillips CM 120 microscope operating at $80 \mathrm{kV}$. 60-nm-thick ultrathin sections of samples obtained by ultramicrotomy.

Differential Scanning Calorimetry (DSC) measurements were performed using a DSC Q10 (TA Instruments) in a dynamic mode, i.e. with a rate of $10{ }^{\circ} \mathrm{C} \mathrm{min}^{-1}$ under nitrogen flow $\left(50 \mathrm{~mL} \mathrm{~min}^{-1}\right)$ from -70 to $300{ }^{\circ} \mathrm{C}$.

Dynamic mechanical analyses (DMA) were performed using parallelepipedic specimens $\left(30 \times 6 \times 3 \mathrm{~mm}^{3}\right)$ in an ARES-G2 rheometer under torsion mode as a function of temperature with a heating rate of $3{ }^{\circ} \mathrm{C}$ $\min ^{-1}$. Storage modulus, $\mathrm{G}^{\prime}$, loss modulus, $\mathrm{G}^{\prime \prime}$, and loss factor, $\tan \delta$, were measured from -120 to $250{ }^{\circ} \mathrm{C}$.
Uniaxial compression tests were performed using a MTS 2/M electromechanical testing system at $22 \pm 1{ }^{\circ} \mathrm{C}$ and $50 \pm 5{ }^{\circ} \mathrm{C}$ relative humidity for a crosshead speed of $1 \mathrm{~mm} \mathrm{~min}^{-1}$ on conventional specimens $\left(5 \times 5 \times 16 \mathrm{~mm}^{3}\right)$. ASTM D695 standard test recommendations were followed. Young's modulus, E, was determined as the slope of the stressstrain curve in the linear domain, i.e. at low strain values. Yield strength, $\sigma_{y}$, was taken, as the maximum stress value on stress-strain curve and the strain and stress at break were determined.

Fracture toughness ( $\left.\mathrm{K}_{\mathrm{IC}}, \mathrm{G}_{\mathrm{IC}}\right)$.

Fracture properties of neat epoxy-amine and epoxy hybrids $\mathrm{O} / \mathrm{I}$ networks were determined using compact tension (CT) specimens following the ISO 13586 standard. The primary V notch was machined with a milling machine and the final sharp crack was created by razor tapping at the edge of the main notch.

The critical stress intensity factor $K_{I C}$ is obtained following the standard procedure, while the fracture energy, $G_{I C}$, in plane stress conditions, was calculated using the following equation (1):

$\boldsymbol{G}_{\boldsymbol{I C}}=K_{I C}^{2} / \boldsymbol{E}\left(1-\boldsymbol{v}^{2}\right)$

where $v$ is the Poisson's ratio (taken to be 0.35 ) and E the Young's modulus.

Surface energy of resulting epoxy networks was determined from the sessile drop method using a GBX goniometer. From contact angle measurements measured with water and diiodomethane as probe liquids, polar and dispersive components of surface energy were determined using Owens-Wendt theory [64].

Thermogravimetric analyses (TGA) were performed using a Q500 thermogravimetric analyzer (TA instruments). The samples were heated from 30 to $900{ }^{\circ} \mathrm{C}$ at $20^{\circ} \mathrm{C} \mathrm{min}^{-1}$ under air.

Flammability was investigated using a pyrolysis combustion flow calorimeter (PCFC from Fire Testing Technology, UK) initially 
developed by Lyon and Walters [65]. The sample $(3 \pm 0.5 \mathrm{mg})$ was heated up to $750{ }^{\circ} \mathrm{C}$ at $1{ }^{\circ} \mathrm{C} \mathrm{s}^{-1}$ in a pyrolyzer under nitrogen flow (anaerobic pyrolysis). The pyrolysis gases were sent to a combustor and mixed with oxygen in excess at $900{ }^{\circ} \mathrm{C}$. In such conditions, these gases were fully oxidized. Heat Release Rate (HRR) was then calculated by oxygen depletion according to Huggett's relation (1 $\mathrm{kg}$ of consumed oxygen corresponds to 13.1 MJ of released energy) [66].

Cone calorimeter experiments were performed using a fire Testing Technology equipment, according to the standard ISO 5660 [67]. Square samples of $100 \times 100 \times 30 \mathrm{~mm}^{3}$ were cut out of larger sheets and their edges polished and wrapped in an aluminum foil leaving only the upper surface apparent to the heater and the lower surface insulated by rock wool. The sample holder was left to cool to room temperature between each test. Every specimen was exposed horizontally under an external heat flow (irradiation) of $35 \mathrm{~kW} \mathrm{~m}^{-2}$. Two specimens were tested for each material and the reported data are the average of the two measurements.

Some tests were recorded using an infrared camera (Optris) placed in an inclined position above the specimen in order to record the temperatures of the top surface. The measured temperature depends not only on the surface temperature but also on the tilt of the apparatus relatively to the surface and the emissivity of the materials. Emissivity was chosen equal to 1 (close to conventional values for polymer materials). In these tests, the distance between the radiant cone and the sample was set to $60 \mathrm{~mm}$. Thereby; the tilt of the infrared camera is only of few degrees relative to the perpendicular position, which limits the error of measurements. The uncontrolled expansion of the specimen during burning can also modify this tilt during the test. Finally, the flame can slightly change the measured temperatures. Further description of such device can be found elsewhere [68].

Scanning electron microscopy (SEM) (performed using FEI Quanta 200 ESEM) at an acceleration voltage of $12.5 \mathrm{kV}$ was used to characterize the microstructure of the residual char of samples after the fire test.

Energy Dispersive X-ray spectroscopy (EDX) using Oxford INCA Energy 300 system and a detector of $133 \mathrm{eV}$ was used to determine elemental compositions of residues from the cone calorimeter tests.

\section{Results and discussion}

\subsection{Curing of epoxy-amine and hybrid $\mathrm{O} / \mathrm{I}$ networks}

First, the curing behavior of the epoxy-amine and the different hybrid O/I networks were evaluated with DSC measurements under dynamic mode in order to highlight the impact of IL-g-POSS ${ }^{\mathrm{Ph}}$ and



Fig. 1. DSC traces of neat epoxy-amine and the hybrid O/I epoxy reactive systems containing $5 \mathrm{wt} \%$ POSS $\AA^{\mathrm{Ph}}$-triol or IL-g-POSS ${ }^{\mathrm{Ph}}{ }^{\mathrm{Ph}}$ with $\mathrm{Cl}^{-}$or $\mathrm{NTf}_{2}$ anion (heating rate: $10{ }^{\circ} \mathrm{C} \mathrm{min}^{-1}$ ).
POSS $\AA^{\mathrm{Ph}}$-triol on the reactivity of the polymerization reaction (Fig. 1). As shown in Fig. 1, all the reactive systems, i.e. DGEBA/IPD without and with unmodified or modified POSS $\AA^{\mathrm{Ph}}$, display an exotherm with a shoulder. According to the literature, such a behavior can be attributed to the adduct formation followed by an addition polymerization $[2,40]$. Nevertheless, two different behaviors were observed. DGEBA/IPD system with and without POSS $\AA^{\mathrm{Ph}}$-triol displays the same behavior with an exothermic peak located at $115{ }^{\circ} \mathrm{C}$ while DGEBA/IPD containing IL-modified POSS ${ }^{\mathrm{Ph}}$ shows a significant decrease of the temperature of the exothermic peak. This shift of the exothermic peak to lower temperatures can be explained by the presence of imidazolium-based ionic liquid well-known to act as catalytic agents of epoxy-amine networks $[54,69,70]$ hence favoring an early initiation of the polymerization. In addition, a slight increase of the total enthalpy value $(\Delta H)$ was observed in presence of IL.Cl-g-POSS $\AA^{\mathrm{Ph}}\left(482.1 \mathrm{~J} \mathrm{~g}^{-1}\right)$ and $\mathrm{IL} . N T f_{2}$-g-POSS ${ }^{\mathrm{Ph}}$ (496.5 $\mathrm{J} \mathrm{g}^{-1}$ ) compared to neat epoxy-amine system $\left(460.4 \mathrm{~J} \mathrm{~g}^{-1}\right)$. Furthermore, the thermograms of hybrid O/I networks containing IL-g-POSS $\AA^{\mathrm{Ph}}$ with different anions show a small additional exothermic peak at higher temperatures $\left(200-250{ }^{\circ} \mathrm{C}\right)$ that can be attributed to the reaction of the imidazolium ionic liquid with epoxy groups [37,54, 70-72]. To confirm this hypothesis, the remaining sol fraction after curing of the different systems was determined. In the case of epoxy networks containing 5 wt $\%$ of POSS $\AA^{\mathrm{Ph}}$-triol, the sol fraction was determined to be $4.8 \%$ which means that POSS $\AA^{\mathrm{Ph}}$-triol clusters are not chemically attached to the epoxy network. For the same amount of IL-grafted POSS $\AA^{\mathrm{Ph}}$, the sol fraction was found to be $3.4 \%$ and $3.6 \%$ for IL.Cl-g-POSS $\AA^{\mathrm{Ph}}$ and IL.NTf ${ }_{2}$-g-POSS ${ }^{\mathrm{Ph}}{ }^{\mathrm{Ph}}$, respectively. Hence, a covalent grafting of these IL-modified POSS ${ }^{\circledR}$ with the epoxy network is ensured for about $30 \%$ of the nanoparticles, while the rest of POSS ${ }^{P h}$ remained unbounded. In summary, all these results suggest that the imidazolium ionic liquid grafted to the POSS ${ }^{\mathrm{Ph}}$-triol with both anions $\left(\mathrm{Cl}^{-}, \mathrm{NTf}_{2}\right)$ acts as an initiator for the ring-opening reaction of the epoxy and a co-curing agent of DGEBA, in agreement with previous studies $[37,70]$.

For all cases, a final epoxy conversion higher than $90 \%$ was obtained confirming the good reactivity of DGEBA and IPD comonomers with and without the presence of unmodified or modified POSS $\AA^{\mathrm{Ph}}$ (see Fig. S4). During the $140{ }^{\circ} \mathrm{C}$ step, a fast consumption of epoxy functions was observed for epoxy containing IL-g-POSS $\AA^{\text {Ph }}$ (see inlet in Fig. S4) whatever the nature of the anion. At 190 and $230{ }^{\circ} \mathrm{C}$, a progressive consumption of epoxy groups was evidenced confirming the DSC results and highlighting a competition between two polymerization mechanisms, i.e. the epoxy-amine condensation reaction and the reaction between IL-g-POSS $\AA^{\mathrm{Ph}}$ and epoxy prepolymer [37].

In conclusion, whatever the anion nature, the reactivity of the imidazolium ionic liquid grafted onto the POSS $\AA^{\mathrm{Ph}}$-triol nanoclusters towards the epoxy prepolymer (DGEBA) compared to the reactivity of the diamine comonomer (IPD) plays a key role on the kinetics of polymerization, and thus on the architecture of the formed hybrid O/I epoxy networks.

\subsection{Morphology of hybrids O/I networks}

Transmission electronic microscopy is a powerful tool to highlight the effect of IL-g-POSS ${ }^{\mathrm{Ph}}$ combined with $\mathrm{Cl}^{-}$or $\mathrm{NTf}_{2}$ on the dispersion of the POSS $\AA^{\mathrm{Ph}}$ nanoclusters into epoxy networks. The morphologies obtained for the different epoxy hybrid O/I networks and the distribu-

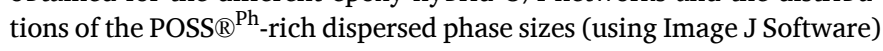
are displayed in Fig. 2 and Fig. 3. In all TEM micrographs, the dark part corresponds to the silicon-rich phases and the bright continuous phase corresponds to the epoxy-amine network.

In all cases, a homogeneous distribution in the epoxy matrix was observed. The POSS ${ }^{P h}$-rich dispersed phase has a spherical or ellipsoidal shape in the different systems with a large diameter distribution ranging from 0.1 to $1.5 \mu \mathrm{m}$ for the hybrid epoxy networks containing POSS ${ }^{\mathrm{Ph}}$-triol. Regarding the literature there is no difference on the 

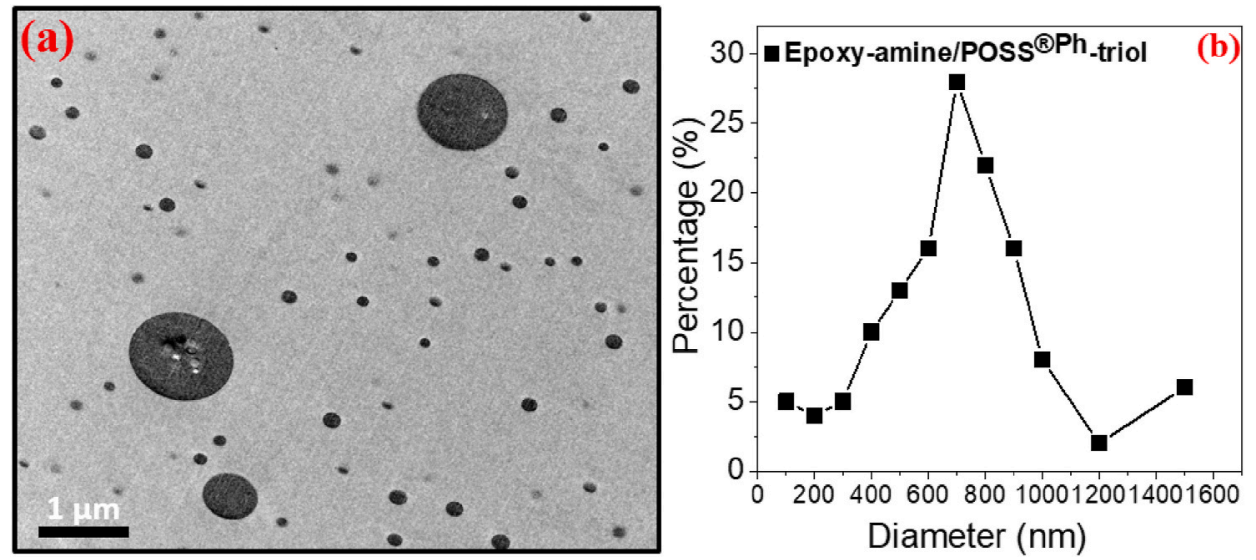

Fig. 2. a) TEM micrograph of the hybrid O/I epoxy network containing POSS $\AA^{\mathrm{Ph}}$-triol, b) Size distribution of POSS $\AA^{\mathrm{Ph}}$-triol aggregates.
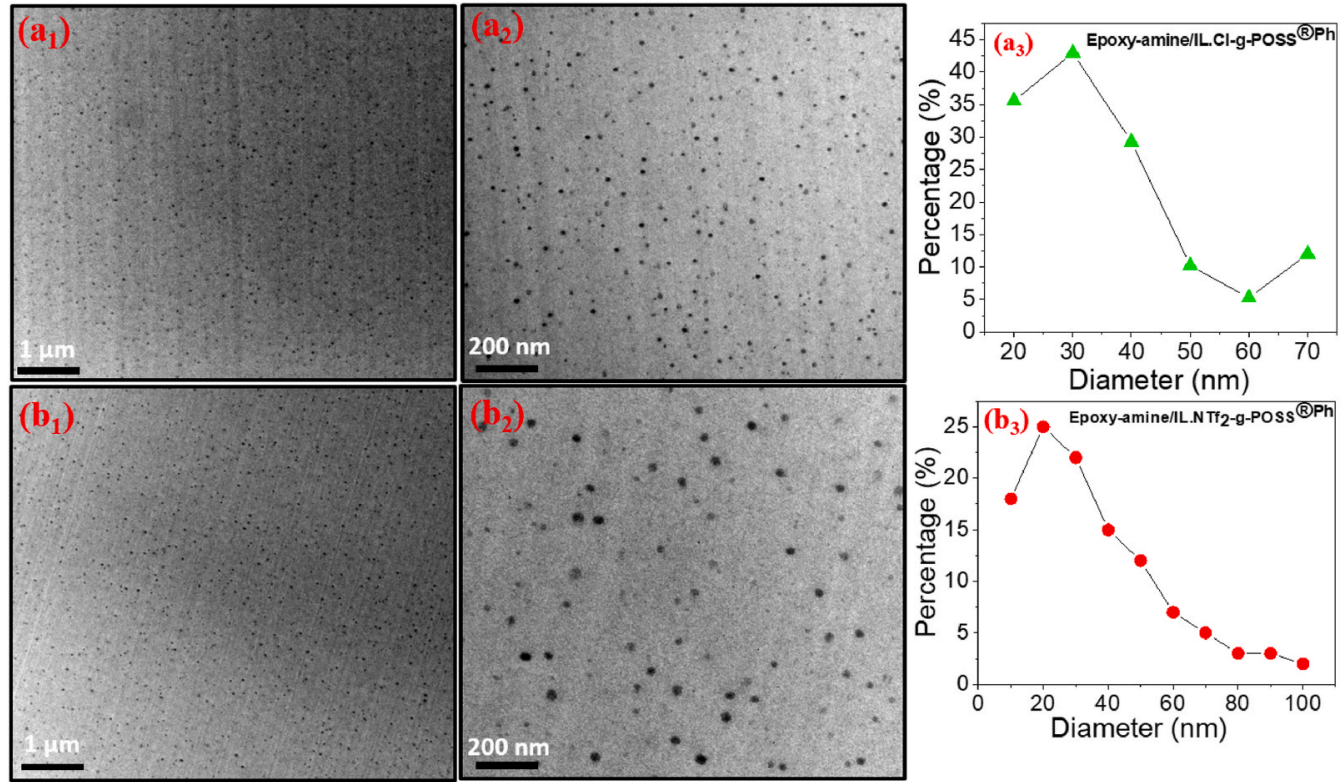

Fig. 3. TEM micrographs of the hybrid O/I epoxy networks containing: a) IL.Cl-g-POSS $\AA^{\mathrm{Ph}}$ at different magnification $\left(\mathrm{a}_{1} ; \mathrm{a}_{2}\right)$, b) IL.NTf $\mathrm{f}_{2}$-g-POSS $\AA^{\mathrm{Ph}}$ at different magnification $\left(b_{1} ; b_{2}\right)$ and their size distribution $\left(a_{3}, b_{3}\right)$.

TEM image between any closed inert POSS $\AA^{\mathrm{Ph}}$ and open $\mathrm{POSS} \AA^{\mathrm{Ph}}$-triol, generally inert POSS ${ }^{\circledR}$ remains undispersed or non-homogeneous dispersed and even tends to agglomerate in the mixing system due to the poor interfacial adhesion $[73,74]$. The POSS $\AA^{\mathrm{Ph}}$-triol can also form hybrids with large aggregates due to the hydroxyl groups of the open cage (POSS $®$-triol) that are well hidden because of hydrogen bonds between POSS $®$-triol particles $[75,76]$. For this reason, several authors try to use some modifiers (metal complex) for better dispersion [75,76]. The epoxy networks containing IL-g-POSS ${ }^{\mathrm{Ph}}$ on the other hand have a narrower diameter distribution ranging only from 10 to $100 \mathrm{~nm}$ whatever the chemical nature of the counter anions $\left(\mathrm{Cl}^{-}\right.$or $\left.\mathrm{NTf}_{2}\right)$. According to the literature, various authors demonstrated that IL-functionalized silica nanoparticles having different counter anions $\left(\mathrm{Cl}^{-}\right.$and $\left.\mathrm{MeSO}_{3}^{-}\right)$ led to well dispersed silica aggregates having a size of few tens of nanometers $[37,38,77]$. Thus, as for nanocomposites based on silica nanoparticles, the imidazolium ILs act as efficient interfacial agents for inorganic-rich nano-objects in epoxy-amine networks.

\subsection{Thermomechanical properties of the resulting networks}

The influence of the unmodified and modified $\operatorname{POSS} \AA^{\mathrm{Ph}}$ on the thermomechanical properties of the epoxy-amine networks was investigated by Dynamic Mechanical Analysis (DMA) (Fig. 4a). The dynamic mechanical spectra of the different epoxy networks allow to determine the storage and loss moduli, as well as the $\tan \delta$ relaxation peaks $\left(\mathrm{T}_{\beta}, \mathrm{T}_{\alpha}\right)$ over a temperature range spanning from -100 to $250{ }^{\circ} \mathrm{C}$. For all the epoxy networks, the narrowness of the main relaxation peak


range suggests that the epoxy-amine networks display a homogeneous structure $[19,78]$. Moreover, all the epoxy networks exhibit a secondary transition at $-60{ }^{\circ} \mathrm{C}$ corresponding to $\beta$-relaxation which is attributed to the local motions of hydroxyether $\left[-\mathrm{CH}_{2}-\mathrm{CH}(\mathrm{OH})-\mathrm{CH}_{2}-\mathrm{O}-\right]$ and bisphenol-A units of the epoxy-amine network [79]. The hybrid O/I epoxy network containing POSS $\AA^{\mathrm{Ph}}$-triol displays the lowest temperature of the $\alpha$-transition $\left(160^{\circ} \mathrm{C}\right)$ as well as the lowest shear modulus in the rubbery state, $\mathrm{G}_{\mathrm{c}}^{\prime}$ (Fig. $4 \mathrm{~b}$ ). This observation suggests that POS$\mathrm{S}{ }^{\mathrm{Ph}}$-triol displays poor interactions at the epoxy-amine network/-


observed morphologies. Indeed, the reaction between the hydroxyl groups from POSS ${ }^{\mathrm{Ph}}$-triol and epoxy functions from the DGEBA prepolymer requires specific conditions to occur, like those reported by Hongzhi et al. [76] who obtained epoxy-POSS ${ }^{\mathrm{Ph}}{ }^{\mathrm{Ph}}$-triol networks only 

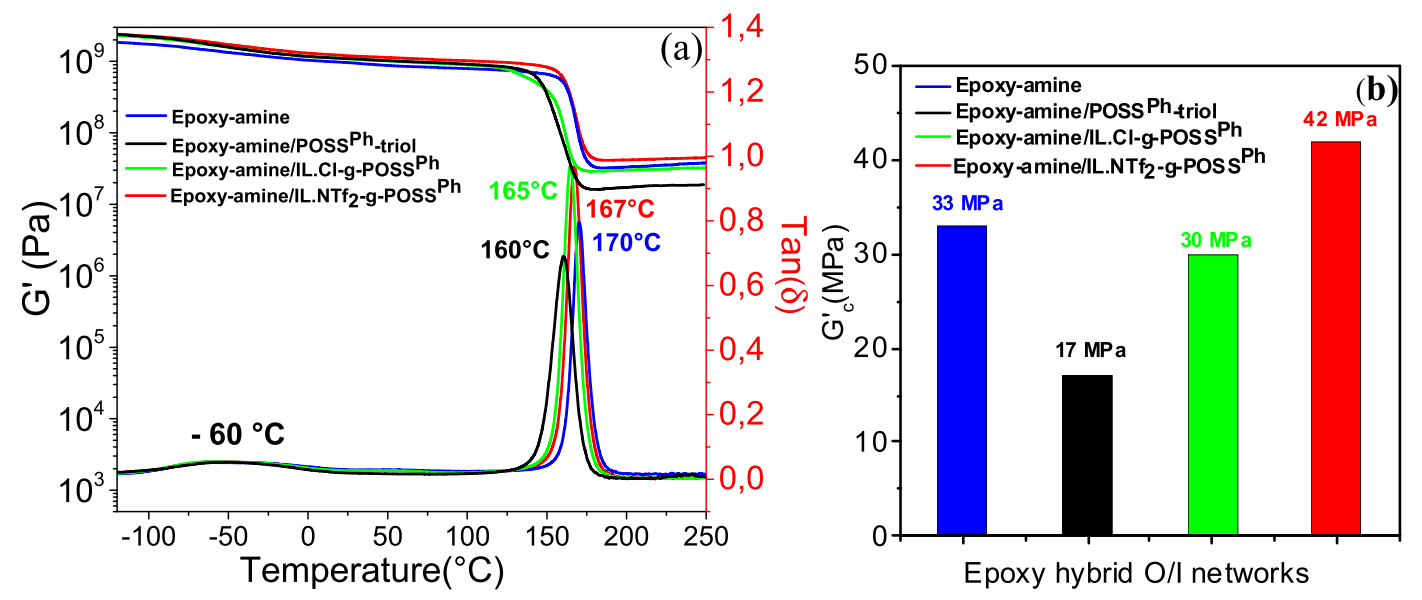

Fig. 4. a) Dynamic mechanical spectra and b) the shear storage moduli, G'c (at 200 triol and IL-g-POSS ${ }^{\mathrm{Ph}}$ with different anions $\left(\mathrm{Cl}^{-}\right.$and $\left.\mathrm{NTf}_{2}\right)$ at $1 \mathrm{~Hz}$.

through the use of a metal complex, aluminum triacetylacetonate (Al), as catalyst. The DMA results are also in a good agreement with the DSC measurements as only one glass transition temperature could be evidenced (see Fig. S5 in the SI). The shear storage moduli, G'c (Fig. 4b), of the rubbery hybrid O/I epoxy networks containing IL-g-POSS ${ }^{\mathrm{Ph}}$ with different anions are slightly higher than the one of the neat epoxy possibly due to a nanoreinforcement effect and a slightly increased crosslinking density. Such behavior is a direct consequence of both chemical bonding and physical interactions generated at the $\mathrm{O} / \mathrm{I}$ interface, i.e. between the ionic liquid-grafted $\operatorname{POSS} \mathbb{R}^{\mathrm{Ph}}$ nano-objects and the epoxy network as well as between POSS ${ }^{\circledR}$ cages and their phenyl ligands [23].

\subsection{Mechanical properties}

\section{a. Elastic and large strain mechanical properties}

The influence of the presence of non-modified and IL-grafted POSS ${ }^{P h}$ on the uniaxial compression response of the different epoxy networks was studied. The values of Young's modulus, yield stress, strain and stress at break are summarized in Table 2. In addition, the stress-strain curves are given in Fig. 5.

The addition of $\mathrm{POSS}{ }^{\mathrm{Ph}}$-triol improves all the measured quantities. However, the presence of IL-g-POSS ${ }_{\mathbb{R}}^{\mathrm{Ph}}$ nanoclusters with both anions $\left(\mathrm{Cl}^{-}\right.$and $\left.\mathrm{NTf}_{2}\right)$ induces an even better reinforcement effect. Increasing both stiffness, yield strength, and the ability to sustain larger deformation and stress at break is not a common feature for highly crosslinked networks even less when they are filled with inorganic nano-objects [80, 81]. For example, Donato et al. [77] considering epoxy-silica nanocomposites and using different imidazolium ILs only as free additive catalysts, reported lower improvements for much higher silica contents (7.5 wt \%), i.e. an increase in the Young's modulus and strain at break up

Table 2

Mechanical properties of the neat epoxy-amine and the hybrid $\mathrm{O} / \mathrm{I}$ epoxy networks measured under uniaxial compression $\left(1 \mathrm{~mm} \mathrm{~min}^{-1} ; 25^{\circ} \mathrm{C}\right)$.

\begin{tabular}{|c|c|c|c|c|}
\hline Material & $\begin{array}{l}\text { Young's } \\
\text { modulus (GPa) }\end{array}$ & $\begin{array}{l}\text { Yield } \\
\text { stress } \\
(\mathrm{MPa})\end{array}$ & $\begin{array}{l}\text { Stress at } \\
\text { break (MPa) }\end{array}$ & $\begin{array}{l}\text { Strain at } \\
\text { break (\%) }\end{array}$ \\
\hline Epoxy-amine & $2.3 \pm 0.1$ & $114 \pm 9$ & $114 \pm 4$ & $28 \pm 2$ \\
\hline 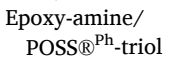 & $2.9 \pm 0.1$ & $131 \pm 9$ & $141 \pm 6$ & $31 \pm 2$ \\
\hline $\begin{array}{l}\text { Epoxy-amine/IL. } \\
{\text { Cl-g-POSS }\left({ }^{P h}\right.}^{P h}\end{array}$ & $3.0 \pm 0.1$ & $166 \pm 11$ & $174 \pm 3$ & $40 \pm 3$ \\
\hline $\begin{array}{l}\text { Epoxy-amine/IL. } \\
\text { NTf }_{2} \text {-g-POSS }{ }^{\mathrm{Ph}}{ }^{\mathrm{Ph}}\end{array}$ & $3.1 \pm 0.1$ & $170 \pm 10$ & $164 \pm 5$ & $40 \pm 2$ \\
\hline
\end{tabular}

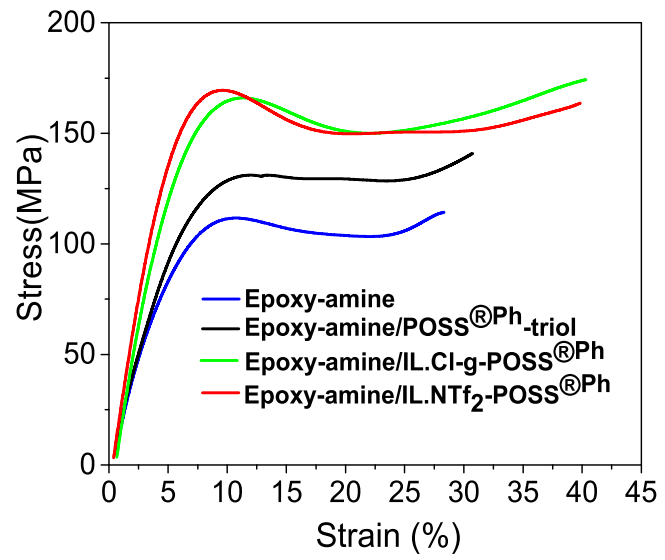

Fig. 5. Stress-strain curves of the neat epoxy-amine and the hybrid $O / I$ epoxy networks.

to 2 and 41\%, respectively. The same group also reported significant improvements of mechanical properties (Young's modulus increased 7\% and strain at break increased $47 \%$ ) by grafting imidazolium IL combined with different anions $\left(\mathrm{Cl}^{-}\right.$and $\mathrm{MeSO}_{3}^{-}$) onto silica particles and with less content of each IL-silica ( $<6.8 \mathrm{wt} \%$ ) [38]. We hypothesize the improved properties we obtained are due to the very fine dispersion of the IL-grafted POSS $\AA^{\mathrm{Ph}}$ nanoclusters into the epoxy-amine network as well as to the strong interactions formed at their interface. Indeed, the grafted imidazolium-based ILs reduce the POSS ${ }^{\mathrm{Ph}}$ aggregation and generate a strong and reversible interaction between nanoclusters and the epoxy-amine matrix. The mutual dipole-ion interaction between IL-g-POSS ${ }^{\mathrm{Ph}}$ nanostructures and the network chains enables a higher cohesion and can sustain larger stresses and strains before breaking.

\section{b. Fracture properties}

The influence of the non-modified and IL-modified $\operatorname{POSS}{ }^{\mathrm{Ph}}$ on the stress intensity factor, $\mathrm{K}_{\mathrm{IC}}$, and fracture toughness, $\mathrm{G}_{\mathrm{IC}}$, of epoxy-based networks was investigated using compact-tension fracture test (CT). The values of the critical stress intensity factor, $\mathrm{K}_{\mathrm{IC}}$, of neat epoxy-amine and epoxy hybrid $\mathrm{O} / \mathrm{I}$ networks are summarized in Table 3.

The fracture properties of the neat epoxy-amine network are in agreement with the literature $[63,82,83]$. In the case of the hybrid O/I epoxy networks based on the different types of POSS ${ }^{\mathrm{Ph}}$, two different behaviors are observed. The hybrid network containing the POS$\mathrm{S} \AA^{\mathrm{Ph}}$-triol displays lower fracture properties compared to the neat 
Table 3

Fracture properties of the neat epoxy-amine and the hybrid O/I epoxy networks.

\begin{tabular}{|c|c|c|}
\hline Material & $\mathrm{K}_{\mathrm{IC}}\left(\mathrm{MPa} \mathrm{m}^{1 / 2}\right)$ & $\mathrm{G}_{\mathrm{IC}}\left(\mathrm{J} \mathrm{m}^{-2}\right)$ \\
\hline Epoxy-amine & $0.71 \pm 0.08$ & $250 \pm 40$ \\
\hline Epoxy-amine $/ \mathrm{POSS} \AA^{\mathrm{Ph}}{ }^{\text {-triol }}$ & $0.61 \pm 0.08$ & $150 \pm 40$ \\
\hline Epoxy-amine/IL.Cl-g-POSS $\AA^{\mathrm{Ph}}$ & $1.02 \pm 0.06$ & $390 \pm 30$ \\
\hline Epoxy-amine/IL.NTf ${ }_{2}$-g-POSS ${ }_{\circledR} \mathrm{Ph}$ & $0.98 \pm 0.06$ & $350 \pm 30$ \\
\hline
\end{tabular}

epoxy-amine network whereas the hybrid O/I epoxy networks containing IL-g-POSS $\AA^{\mathrm{Ph}}$ exhibit higher $\mathrm{K}_{\mathrm{IC}}$ and $\mathrm{G}_{\mathrm{IC}}$. As shown in Fig. 3, this difference can be attributed to the smaller $(10-100 \mathrm{~nm})$ and more uniform and well-dispersed POSS $\AA^{\mathrm{Ph}}$ aggregates for IL-g-POSS $\AA^{\mathrm{Ph}}$ hybrids whatever the nature of the anion $\left(\mathrm{Cl}^{-}\right.$or $\left.\mathrm{NTf}_{2}\right)$ as well as to their improved interfacial interactions. While, the non-grafted $\operatorname{POSS}{ }^{\mathrm{Ph}}{ }^{\mathrm{Ph}}$, which are assembled in larger (up to micron-size) and less cohesive aggregates, act as local defects leading to a lower crack propagation resistance. According to the literature, ILs can act as dispersing agents for high- $\mathrm{T}_{\mathrm{g}}$ thermoplastics [84], core-shell particles [85,86], or nanoparticles added to epoxy networks and have a significant influence on the fracture toughness of the modified networks [77,84,87-89]. Also, as $\mathrm{K}_{\mathrm{IC}}$ is known to be strongly affected by the nanocomposites morphology and interfacial characteristics, a fine dispersion of such stiffer fillers ensures the promotion of efficient toughening mechanisms: increase of the process zone size, crack pinning and branching leading to a deviation of the crack propagation $[38,77,90]$.

\subsection{Surface properties}

Surface energies of the neat epoxy-amine and the hybrid O/I epoxy networks were determined by the sessile drop method using OwensWendt theory [64]. Therefore, the non-dispersive and dispersive components were calculated from the water and methylene diiodide contact angles (Table 4).

In all cases, the addition of 5 wt $\%$ of unmodified (POSS $\AA^{\mathrm{Ph}}$-triol) or IL-grafted modified POSS ${ }^{\mathrm{Ph}}$ leads to a decrease of the surface energy, which results from the combined reductions of the dispersive and nondispersive components. These results can be explained by the hydrophobic character of the POSS $₫$ molecules composed of phenyl ligands [91]. However, the grafting of POSS ${ }^{\mathrm{Ph}}$ with imidazolium ionic liquids also plays a key role in the hydrophobicity of the epoxy network as shown by the significantly decreased surface energy for systems containing IL-modified POSS $\AA^{\mathrm{Ph}}$ (Table 4). Indeed, the values obtained here are similar to the ones measured for different fluorinated polymers such as PTFE [92]. This surface behavior can be clearly attributed to the presence of the imidazolium IL which is well-known to have low surface tension [93]. According to the literature, the incorporation of various amounts of phosphonium or imidazolium ILs into epoxy networks leads to the formation of highly hydrophobic networks opening many perspectives in the field of paints and coatings. These surface energy are also lower than ones measured on epoxy modified by fillers with $3.5 \mathrm{phr}$

Table 4

Determination of dispersive and non-dispersive components of the surface energy of the neat epoxy-amine and the hybrid O/I epoxy networks from contact angles with water and methylene diiodide.

\begin{tabular}{|c|c|c|c|c|c|}
\hline Samples & $\begin{array}{l}\Theta \text { Water } \\
\left({ }^{\circ}\right)\end{array}$ & $\begin{array}{l}\Theta_{\mathrm{CH} 2 \mathrm{I} 2} \\
\left({ }^{\circ}\right)\end{array}$ & $\begin{array}{l}\gamma_{\text {non-dispersive }} \\
\left(\mathrm{mJ} \mathrm{m}^{-2}\right)\end{array}$ & $\begin{array}{l}\gamma_{\text {dispersive }} \\
\left(\mathrm{mJ} \mathrm{m}^{-2}\right)\end{array}$ & $\begin{array}{l}\gamma_{\text {total }} \\
(\mathrm{mJ} \\
\left.\mathrm{m}^{-2}\right)\end{array}$ \\
\hline Epoxy-amine & 79 & 49 & 4.8 & 34.8 & 39.6 \\
\hline $\begin{array}{l}\text { Epoxy-amine/ } \\
{\text { POSS }{ }^{P h}}^{\text {-triol }}\end{array}$ & 96 & 51 & 0.7 & 33.4 & 34.1 \\
\hline $\begin{array}{l}\text { Epoxy-amine/IL. } \\
\text { Cl-g-POSS }{ }^{P h}\end{array}$ & 99 & 64 & 0.4 & 26.2 & 26.6 \\
\hline $\begin{array}{l}\text { Epoxy-amine/IL. } \\
\text { NTf }_{2-} \text { - } \\
\operatorname{POSS}_{(}{ }^{\mathrm{Ph}}\end{array}$ & 105 & 67 & 0.5 & 22.7 & 23.2 \\
\hline
\end{tabular}

of silica [94] or $10 \mathrm{phr}$ of amphiphilic triblock copolymer bearing a poly (butadiene-g-POSS $\AA$ block) [95]. Similar results were also found in the literature when using high amount (10 wt \%) of POSS ${ }^{\circledR}$-capped poly (ethylene oxide) $[96,97]$.

\subsection{Thermal-oxidative stability}

The weight loss as a function of temperature under air atmosphere as well as the initial decomposition temperature $\left(\mathrm{T}_{\mathrm{d} 5 \%}\right)$ and the maximal degradation temperature $\left(\mathrm{T}_{\mathrm{dmax}}\right)$ of the hybrid $\mathrm{O} / \mathrm{I}$ epoxy networks was measured by TGA and are presented in Fig. $6 \mathrm{a}$ and $\mathrm{b}$.

The TGA traces of the hybrid O/I epoxy networks display the same decomposition behavior as the neat epoxy-amine network, which is characterized by two decomposition steps. The first and biggest weight loss occurs from 350 to $500{ }^{\circ} \mathrm{C}$ corresponds to the simultaneous decomposition of the organic matrix, IL, and phenyl ligands of the POSS $®$ cages as well as the formation of carbonaceous compounds. During the second step of thermal degradation occurring from 500 to $650{ }^{\circ} \mathrm{C}$, these carbonaceous compounds are eventually oxidized and volatilized [98]. An increase of the thermal stability of epoxy networks containing POSS $\AA^{\mathrm{Ph}}$ nano-objects compared to the neat epoxy-amine network is clearly observed. It is worth noting that the epox$\mathrm{y} / \mathrm{IL}-\mathrm{g}-\mathrm{POSS} \mathbb{R}^{\mathrm{Ph}}$ hybrids with different anions types exhibit a higher stability compared to the epoxy/POSS ${ }_{\circledR}{ }^{\mathrm{Ph}}$-triol hybrid. In addition, the presence of the NTf2-anion improves better the thermal stability, especially the resistance to oxidation during the second step (see Fig. 6b). This phenomena can be explained from the existence of improved interfacial interactions between the epoxy matrix and the IL-grafted POSS $\AA^{\mathrm{Ph}}[99,100]$ and the nanoscale dispersion of the later nano-objects acting as a more efficient barrier against heat and oxygen transport [22]. In fact, well-dispersed POSS $®$ nanoclusters at the molecular level can suppress mass loss from segmental decomposition via gaseous fragments. Such behavior is very similar to the one reported in the literature for fully exfoliated clay-polymer nanocomposites [33]. In summary, a real synergistic effect between $\operatorname{POSS} \AA^{\mathrm{Ph}}$ and ionic liquids takes place leading to a significant increase of the thermal stability of the resulting networks.

\subsection{Fire resistance}

a. Flammability data from PCFC tests are listed in Table 5 and HRR curves are plotted versus temperature in Fig. 7 for the different hybrid O/I epoxy networks.

b. Fire behavior of the neat epoxy-amine, the hybrid O/I epoxy networks was evaluated with cone calorimeter experiments, closer to real-word fire conditions. Indeed, PCFC cannot assess some phenomena as barrier effect. The HRR curves, displayed in Fig. 8, come as a support for Table 6 that lists the following data extracted from the cone calorimeter tests: time to ignition (TTI, in second), total heat released (THR, in $\mathrm{kJ} \mathrm{g}^{-1}$ ), peak of heat release rate (pHRR, in $\mathrm{kW}$ $\mathrm{m}^{-2}$ ), residual weight (RW in \%), effective heat of combustion (EHC, in $\mathrm{kJ} \mathrm{g}^{-1}$ ), and total smoke released (TSR in $\mathrm{m}^{-2}$ ). Inspection of the char residues morphology was also carried out.

Peak of heat release rate (pHRR) and Total heat release (THR) are respectively $559 \mathrm{~W} \mathrm{~g}^{-1}$ and $29.4 \mathrm{~kJ} \mathrm{~g}^{-1}$ for the neat epoxy-amine network and are in a good agreement with previously published data [101]. The O/I hybrid epoxy network containing POSS $\AA^{\mathrm{Ph}}$-triol does not exhibit much better flammability properties. In fact, pHRR is just slightly lower and appears at the same temperature while THR is reduced to $26.9 \mathrm{~kJ} \mathrm{~g}^{-1}$. Nevertheless, the residue content is slightly increased (from 6 to 15 wt \%). Both hybrid O/I epoxy networks containing IL.Cl-g-POSS ${ }^{\mathrm{Ph}}$ and IL.NTf ${ }_{2}$-g-POSS ${ }^{\mathrm{Ph}}$ also show better performances than the neat epoxy-amine network and the network containing POSS $\AA^{\mathrm{Ph}}$-triol. Even if the temperature at peak is similar for both hybrids, epoxy-amine/IL.NTf 2 -g-POSS $\AA^{\mathrm{Ph}}$ also appears to be 



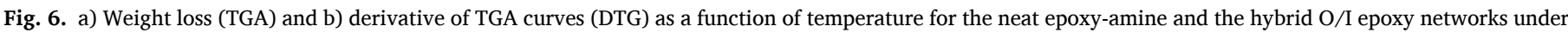
air atmosphere $\left(10{ }^{\circ} \mathrm{C} \mathrm{min}^{-1}\right)$.

Table 5

PCFC data of the neat epoxy-amine and the hybrid O/I epoxy networks.

\begin{tabular}{llllll}
\hline Material & $\begin{array}{l}\text { pHRR }(\mathrm{W} \\
\left.\mathrm{g}^{-1}\right)\end{array}$ & $\begin{array}{l}\text { TpHRR } \\
\left({ }^{\circ} \mathrm{C}\right)\end{array}$ & $\begin{array}{l}\text { THR }(\mathrm{kJ} \\
\left.\mathrm{g}^{-1}\right)\end{array}$ & $\begin{array}{l}\text { Residue } \\
(\mathrm{wt} \%)\end{array}$ & $\begin{array}{l}\Delta \mathrm{h}(\mathrm{kJ} \\
\left.\mathrm{g}^{-1}\right)\end{array}$ \\
\hline $\begin{array}{l}\text { Epoxy-amine } \\
\text { Epoxy-amine/ } \\
\quad \text { POSS } \AA^{\mathrm{Ph}} \text {-triol }\end{array}$ & 559 & 382 & 29.4 & 6 & 31.1 \\
$\begin{array}{c}\text { Epoxy-amine/IL. } \\
\text { Cl-g-POSS }{ }^{\mathrm{Ph}}\end{array}$ & 418 & 379 & 26.9 & 15 & 31.6 \\
$\begin{array}{c}\text { Epoxy-amine/IL. } \\
\mathrm{NTf}_{2} \text {-g-POSS }{ }^{\mathrm{Ph}}\end{array}$ & 409 & 447 & 26.5 & 9 & 29.2 \\
\hline
\end{tabular}

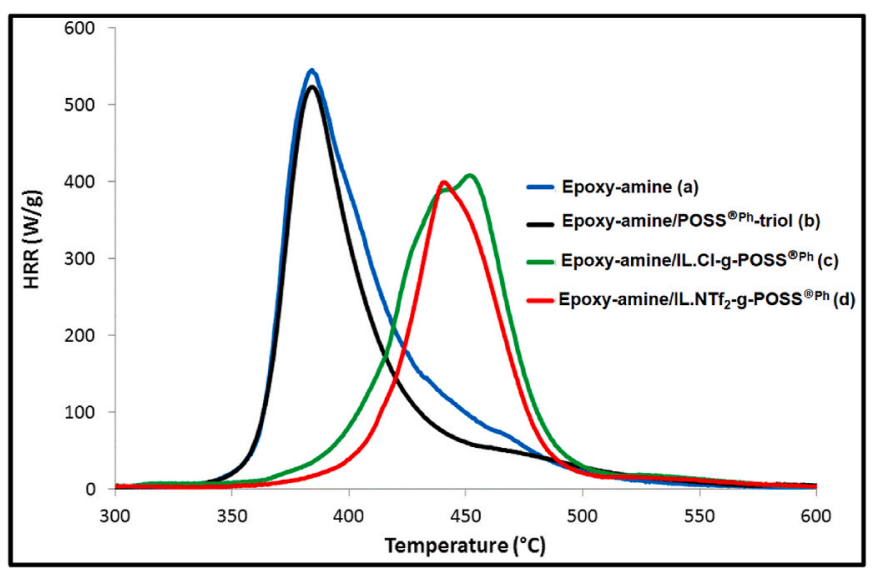

Fig. 7. PCFC HRR traces of the neat epoxy-amine, and the hybrid $\mathrm{O} / \mathrm{I}$ epoxy networks.

slightly more thermally stable at low temperatures (in the range $350-450{ }^{\circ} \mathrm{C}$ ). Heat of complete combustion, $\Delta \mathrm{h}$, is in the range $29-32 \mathrm{~kJ}$ $\mathrm{g}^{-1}$, except for epoxy-amine/IL.NTf $2_{2}$-g-POSS ${ }^{\mathrm{Ph}}\left(25.5 \mathrm{~kJ} \mathrm{~g}^{-1}\right)$ confirming once again its best flammability-resistance. One can notice that no additional peak is evidenced at high temperatures (above $500{ }^{\circ} \mathrm{C}$ ) as observed in TGA. In fact, the second TGA peak is attributed to the thermo-oxidation of residues while pyrolysis in PCFC is performed under anaerobic conditions thus inhibiting this second step.

TTI is used to determine the influence of a flame-retardant on ignitability. For the hybrid O/I networks, TTI does not decrease in comparison to neat epoxy-amine network. Such a stability of TTI is very valuable for enhancement of the flame-retardancy properties of epoxy resins [30]. Indeed, phosphorus compounds are efficient fire-retardant additives promoting charring and reducing heat release rate in epoxy resins; unfortunately, most of them also enable an earlier ignition due to

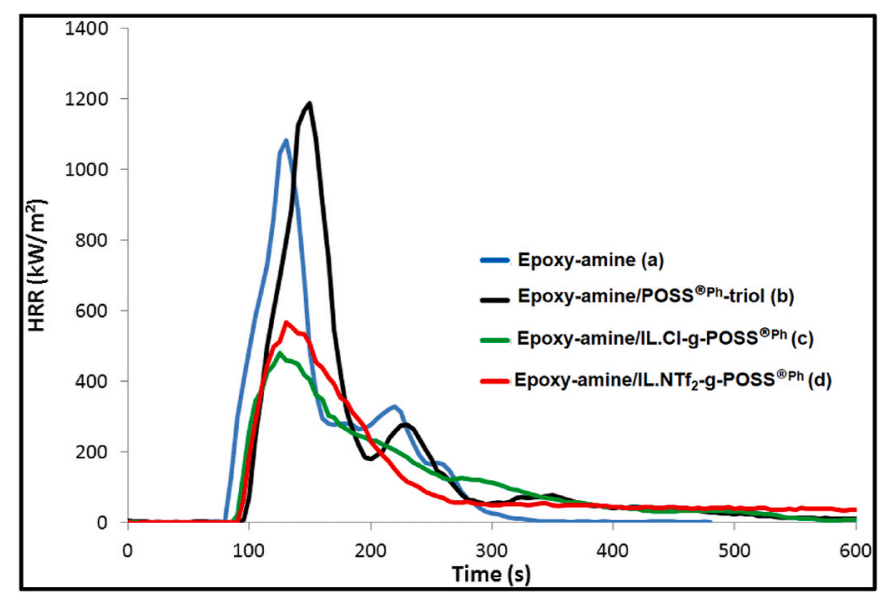

Fig. 8. Cone calorimeter HRR curves of the neat epoxy-amine, and the hybrid O/I epoxy networks.

Table 6

Cone calorimeter data of the neat epoxy-amine, the hybrid O/I epoxy networks.

\begin{tabular}{|c|c|c|c|c|c|c|}
\hline Material & $\begin{array}{l}\text { TTI } \\
\text { (s) }\end{array}$ & $\begin{array}{l}\text { THR } \\
\left(\mathrm{kJ} \mathrm{g}^{-1}\right)\end{array}$ & $\begin{array}{l}\mathrm{pHRR} \\
\left(\mathrm{kW} \mathrm{m}^{-2}\right)\end{array}$ & $\begin{array}{l}\text { RW } \\
(\%)\end{array}$ & $\begin{array}{l}\mathrm{EHC} \\
\left(\mathrm{kJ} \mathrm{g}^{-1}\right)\end{array}$ & $\begin{array}{l}\text { TSR } \\
\left(\mathrm{m}^{2}\right)\end{array}$ \\
\hline Epoxy-amine & 82 & 22.2 & 1084 & 11.5 & 25.1 & 25.0 \\
\hline $\begin{array}{l}\text { Epoxy-amine/ } \\
{\text { POSS }{ }^{\mathrm{Ph}}{ }^{-} \text {-triol }}\end{array}$ & 92 & 22.2 & 983 & 11.7 & 25.1 & 25.1 \\
\hline $\begin{array}{l}\text { Epoxy-amine/IL. } \\
{\text { Cl-g-POSS }{ }^{\mathrm{Ph}}}^{\text {Cl-P }}\end{array}$ & 94 & 20.7 & 480 & 6.3 & 22.2 & 24.1 \\
\hline $\begin{array}{l}\text { Epoxy-amine/IL. } \\
\text { NTf }_{2^{-}} \text {- } \\
\text { POSS }_{\mathbb{R}}{ }^{\mathrm{Ph}}\end{array}$ & 106 & 20.8 & 508 & 9.8 & 23.2 & 23.1 \\
\hline
\end{tabular}

the deterioration of epoxy thermal stability by phosphoric acids while the present materials avoid this drawback.

HRR curves for a, and b (Fig. 8) show a sharp pHRR followed by a fast decrease to flame out. Such curves are indicative of a fast and uncontrolled burning. The neat epoxy-amine network is highly flammable and the HRR shows a sharp peak heat release rate (pHRR) of $1084 \mathrm{~kW} \mathrm{~m}^{-2}$. When the POSS ${ }^{\mathrm{Ph}}$-triol is added, the pHRR remains close to $1000 \mathrm{~kW}$ $\mathrm{m}^{-2}$ while the two IL-g-POSS $\AA^{\mathrm{Ph}}$ modified epoxy networks exhibit a significant decrease. In several cases, a second peak is observed at the end of the test. pHRR for $\mathrm{c}$ and $\mathrm{d}$ are much lower ( 480 and $508 \mathrm{~kW} \mathrm{~m}^{-2}$ ) and a progressive decrease of HRR is observed from $250 \mathrm{~s}$ to flame out due to slow thermo-oxidation of the residue (flame is reduced and does not cover the whole sample, therefore thermo-oxidation can occur). These curves show that these samples highlight a so-called thick- 
charring behavior, i.e. the accumulation of a stable residue limiting the heat transfer from the flame to the outer part of the material slowing down its pyrolysis [101]. The lack of additional peak at the end of burning may be ascribed to a quite good protective effect of the residue.

The combustion efficiency, i.e. the ratio between the effective heat of combustion and the heat of complete combustion measured in PCFC, is in the range of $0.76-0.90$ for polymeric materials. It is not significantly lower for epoxy-amine containing IL.Cl-g-POSS ${ }^{\mathrm{Ph}}$ despite the release of chlorine-containing gases. Chlorine is not detected in the residue from EDX analyses. Nevertheless, this halogen is well known to act as flame poisoner but is probably in too low content to be effective here.

Photographs of post-fire residues obtained after the cone calorimeter experiments are shown in Fig. S6 in the SI. As can be seen, the neat epoxy-amine, and the hybrid O/I epoxy containing POSS ${ }^{\mathrm{Ph}}{ }^{\mathrm{h}}$-triol and IL.Cl-g-POSS $\AA^{\mathrm{Ph}}$ networks left a small and poorly cohesive dome-like char whose top part has collapsed. On the contrary, for the hybrid O/I epoxy containing IL-g-POSS $\AA^{\mathrm{Ph}}$ with $\mathrm{NTf}_{2}$ anion (Fig.S6d of SI, the residue has swollen distinctly, and the top layer is white and still seems protective. EDX and SEM analysis were carried out on the upper and lower layers of the residue for the epoxy-amine/IL.NTf ${ }_{2}$-g-POSS ${ }_{\circledR}{ }^{\mathrm{Ph}}$ network (Fig. S7 of SI). On one hand, the top layer appears as a dense porous homogeneous network. More surprisingly, it does not contain carbon and the proportions of oxygen and silicon are very close to the theoretical ones for silica. We can thus assume this upper surface is pure silica. Such layer is not observed for the other hybrids for which the silicon content in residue remains close to $10 \mathrm{wt} \%$. On the other hand, the bottom surface of epoxy-amine/IL.NTf 2 -g-POSS ${ }^{\mathrm{Ph}}$ is completely different and exhibits a composition closer to the original network. Such a top layer may be mechanically stable enough to enhance the fire resistance of the composite material, but this assumption needs further investigation.

The whole burning process was recorded using both an optical and a thermal camera to get new insights on the decomposition kinetics of the epoxy containing IL-g-POSS $\mathbb{R}^{\mathrm{Ph}}$ (note that the pictures and the temperature curves do not correspond exactly to the HRR curves in Fig. 7 because the distance between radiant cone and samples was increased from 25 to $60 \mathrm{~mm}$ ). The optical pictures in Fig. S8 of SI follow the combustion of the hybrid O/I epoxy networks containing IL.NTf $2_{2}$-gPOSS $\AA^{\mathrm{Ph}}$ and IL.Cl-g-POSS $\AA^{\mathrm{Ph}}$ respectively. It can be seen that the expansion of both char layers occurs slowly and only around 200 s, i.e. well after the peak of heat release rate, when the HRR is decreased at a lower level. It means that the expansion is not responsible for the better fire performances of these materials. For epoxy-amine/IL.NTf $2_{2}$ gPOSS ${ }^{\mathrm{Ph}}$, the flames are observed shortly after and only on the edges of the sample. Therefore, thermo-oxidation can occur and char is progressively removed from the surface, which becomes white (i.e. corresponding to the silica layer, as discussed above). Nevertheless, the surface remains cohesive without any cracks. In contrast, for epoxyamine/IL.Cl-g-POSS ${ }^{\circledR}{ }^{\mathrm{Ph}}$, cracks are observed very quickly (after $200 \mathrm{~s}$ white arrow) but the cracks develop slowly and the char residue fully breaks only at the end of the test.

Fig. 9 shows the pictures of both networks recorded from the thermal camera. While the surface appears unchanged during the whole test for epoxy-amine/IL.NTf $2_{2}-\mathrm{g}$-POSS ${ }^{\mathrm{Ph}}{ }^{\mathrm{Ph}}$, the formation of cracks (indicated by a white arrow) and the final breaking of the residue layer is clearly shown for epoxy-amine/IL.Cl-g-POSS ${ }_{\circledR}^{\mathrm{Ph}}$ confirming the observations from Fig. S8-b in the SI.

As a conclusion, the use of ionic liquid grafted onto the POSS $\AA^{\mathrm{Ph}}$ cages whatever the nature of the anion $\left(\mathrm{Cl}^{-}\right.$or NT娄) gives a significant enhancement on the pHRR compared to the neat epoxy network. These results are much better than those of epoxy-amine/POSS ${ }^{\mathrm{Ph}}$-triol modified with the aluminum triacetylacetonate (Al) $[5,98]$ or with 9 , 10-dihydro-9-oxa-10-phosphaphenanthrene-10-oxide (DOPO) [30, 102]. A similar effect was also found in fully layered silicate-epoxy nanocomposites but with higher ignitability $[103,104]$. This enhancement on fire behavior can be explained not only by the nanodispersion of

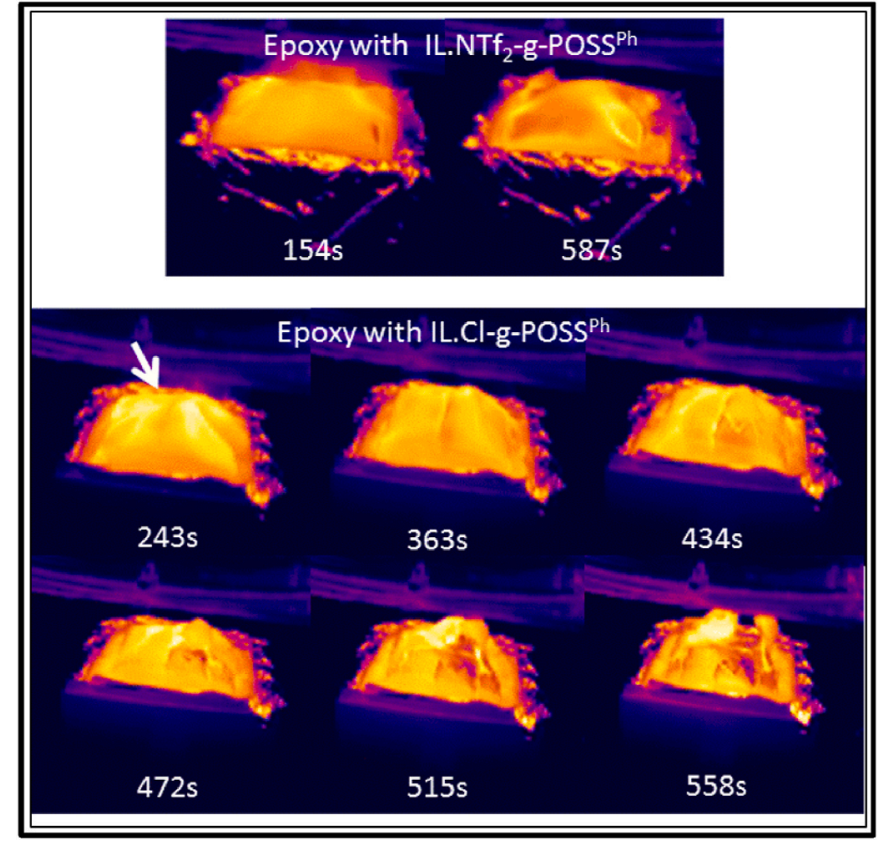

Fig. 9. Pictures obtained using thermal camera from cone calorimeter test of the hybrid $\mathrm{O} / \mathrm{I}$ epoxy networks containing IL.NTf ${ }_{2}$-g-POSS ${ }^{\mathrm{Ph}}$ and IL.Clg-POSS ${ }^{\mathrm{Ph}}$.

POSS $\AA^{\mathrm{Ph}}$ moieties but also by the nature of the IL (cation/anion) associated to the POSS ${ }^{\mathrm{Ph}}$ cages, which affects the thermal stability and the combustion process [30]. Even if pHRR is in the same range for both epoxy networks containing IL.Cl-g-POSS ${ }^{\mathrm{Ph}}{ }^{\mathrm{and}}$ al..NTf ${ }_{2}$-g-POSS ${ }^{\mathrm{Ph}}{ }^{\mathrm{Ph}}$, it can be assumed that IL-g-POSS $\AA^{\mathrm{Ph}}$ with $\mathrm{NTf}_{2}^{-}$anion allows creating a well-organized and compact residue on the top surface of the epoxy composite, which may limit more efficiently the heat diffusion in the condensed phase in other fire conditions.

\section{Conclusions}

In this work, IL-grafted polyhedral oligomeric silsesquioxanes (IL-gPOSS $\AA^{\mathrm{Ph}}$ ) were successfully designed and used as modifiers of a standard epoxy-amine network (DGEBA/IPD). The incorporation of a low amount (5 wt \%) of such organic-inorganic and ionic hybrid nanoobjects lead to the fine nanostructuration of multifunctional epoxybased thermosets. We demonstrated that the chemical nature of the counter anion, i.e. chloride $\left(\mathrm{Cl}^{-}\right)$versus bistriflimide $\left(\mathrm{NTf}_{2}^{-}\right)$, has no influence on the polymerization kinetics. However, due to the catalytic effect of the IL, it plays a key role on the final properties of the resulting networks thanks to the formation of strong interactions between the epoxy network and the IL-grafted POSS $\AA^{P h}$. The introduction of IL-gPOSS $\AA^{\mathrm{Ph}}$ thus contributed to a significant improvement of the mechanical properties of the obtained networks, i.e. both stiffness and toughness were increased without any decrease of the glass transition temperature. Moreover, the fire retardancy of the hybrid O/I epoxy networks was also more specifically evaluated from pyrolysiscombustion flow calorimetry (PCFC) and cone calorimeter analyses. These first results clearly highlighted the promising synergistic effect of POSS ${ }^{\mathrm{Ph}}$ nanoclusters combined to imidazolium ILs inducing impressive reductions of the pHRR (55\%) and an important retardancy effect by significantly increasing the ignition time. Hence, IL modified POSS ${ }^{\circledR}$ can be envisioned as a novel alternative for FR additive that non-only shows efficient fire resistance capabilities but also improves the mechanical properties of the obtained epoxy composite. Finally, the grafting of POSS $\AA^{\mathrm{Ph}}$ by ILs definitely opens new interesting perspectives in the fine-tuning of interfacial interactions of polymer nanocomposites. 


\section{Funding}

This research received no external funding.

\section{Declaration of competing interest}

The authors declare that they have no known competing financial interests or personal relationships that could have appeared to influence the work reported in this paper.

\section{Appendix A. Supplementary data}

Supplementary data to this article can be found online at https://doi. org/10.1016/j.polymer.2021.123721.

\section{References}

[1] E. Petrie, Epoxy Adhesive Formulations (McGraw-Hill Chemical Engineering), McGraw-Hill Professional New York, NY, 2005.

[2] J.P. Pascault, R.J. Williams, Epoxy Polymers: New Materials and Innovations, John Wiley \& Sons, 2009.

[3] T. Vidil, F. Tournilhac, S. Musso, A. Robisson, L. Leibler, Control of reactions and network structures of epoxy thermosets, Prog. Polym. Sci. 62 (2016) 126-179.

[4] B.J. Rohde, K.M. Le, R. Krishnamoorti, M.L. Robertson, Thermoset blends of an epoxy resin and polydicyclopentadiene, Macromolecules 49 (2016) 8960-8970.

[5] S. Laik, J. Galy, J.F. Gérard, M. Monti, G. Camino, Fire behaviour and morphology of epoxy matrices designed for composite materials processed by infusion, Polym. Degrad. Stabil. 127 (2016) 44-55.

[6] N. Saba, M. Jawaid, M. Paridah, O. Al-Othman, A review on flammability of epoxy polymer, cellulosic and non-cellulosic fiber reinforced epoxy composites, Polym. Adv, Technol. 27 (2016) 577-590.

[7] J. Hodgkin, G. Simon, R.J. Varley, Thermoplastic toughening of epoxy resins: a critical review, Polym. Adv. Technol. 9 (1998) 3-10.

[8] M. Frigione, L. Mascia, D. Acierno, Oligomeric and polymeric modifiers for toughening of epoxy resins, Eur. Polym. J. 31 (1995) 1021-1029.

[9] R. Bagheri, B. Marouf, R. Pearson, Rubber-toughened epoxies: a critical review, J. Macromol. Sci. Polymer Rev. 49 (2009) 201-225.

[10] S. Kemmlein, D. Herzke, R.J. Law, Brominated flame retardants in the European chemicals policy of REACH-Regulation and determination in materials, $\mathrm{J}$ Chromatogr (2009) 320-333. A 1216.

[11] H. Ren, J. Sun, B. Wu, Q. Zhou, Synthesis and properties of a phosphoruscontaining flame retardant epoxy resin based on bis-phenoxy (3-hydroxy) phenyl phosphine oxide, Polym. Degrad. Stabil. 92 (2007) 956-961.

[12] A. Toldy, B. Szolnoki, G. Marosi, Flame retardancy of fibre-reinforced epoxy resin composites for aerospace applications, Polym. Degrad. Stabil. 96 (2011) 371-376.

[13] A. Buchman, H. Dodiuk-Kenig, A. Dotan, R. Tenne, S. Kenig, Toughening of epoxy adhesives by nanoparticles, J. Adhes. Sci. Technol. 23 (2009) 753-768.

[14] H.S. Ababsa, Z. Safidine, A. Mekki, Y. Grohens, A. Ouadah, H. Chabane, Fire behavior of flame-retardant polyurethane semi-rigid foam in presence of nickel (II) oxide and graphene nanoplatelets additives, J. Polym. Res. 28 (2021) 1-14.

[15] H. Yari, M. Mohseni, M. Messori, Toughened acrylic/melamine thermosetting clear coats using POSS $®$ molecules: mechanical and morphological studies, Polymer 63 (2015) 19-29.

[16] K. Mishra, R.P. Singh, Quantitative evaluation of the effect of dispersion techniques on the mechanical properties of polyhedral oligomeric silsesquioxane (POSS (R)-epoxy nanocomposites, Polym, Compos (2018) 1-9.

[17] D.B. Cordes, P.D. Lickiss, F. Rataboul, Recent developments in the chemistry of cubic polyhedral oligosilsesquioxanes, Chem. Rev. 110 (2010) 2081-2173.

[18] R.M. Laine, J. Choi, I. Lee, Organic-inorganic nanocomposites with completely defined interfacial interactions, Adv. Mater 13 (2001) 800-803.

[19] J. Choi, A.F. Yee, R.M. Laine, Toughening of cubic silsesquioxane epoxy nanocomposites using core-shell rubber particles: a three-component hybrid system, Macromolecules 37 (2004) 3267-3276.

[20] J. Choi, A.F. Yee, R.M. Laine, Organic/inorganic hybrid composites from cubic silsesquioxanes. epoxy resins of octa (dimethylsiloxyethylcyclohexylepoxide) silsesquioxane, Macromolecules 36 (2003) 5666-5682.

[21] J. Choi, R. Tamaki, S.G. Kim, R.M. Laine, Organic/inorganic imide nanocomposites from aminophenylsilsesquioxanes, Chem. Mater. 15 (2003) 3365-3375.

[22] J. Choi, S.G. Kim, R.M. Laine, Organic/inorganic hybrid epoxy nanocomposites from aminophenylsilsesquioxanes, Macromolecules 37 (2004) 99-109.

[23] L. Matějka, P. Murias, J. Pleštil, Effect of POSS $®$ on thermomechanical properties of epoxy-POSS $®$ nanocomposites, Eur. Polym. J. 48 (2012) 260-274.

[24] C. Zhang, T. Li, H. Song, Y. Han, H. Su, Y. Wang, Q. Wang, Epoxy resin/POSS $\mathbb{R}$ nanocomposites with toughness and thermal stability, J. Photopolym. Sci. Technol. 30 (2017) 25-31.

[25] J. Fu, L. Shi, Y. Chen, S. Yuan, J. Wu, X. Liang, Q. Zhong, Epoxy nanocomposites containing mercaptopropyl polyhedral oligomeric silsesquioxane: morphology, thermal properties, and toughening mechanism, J. Appl. Polym. Sci. 109 (2008) 340-349.
[26] M.A. Abdelwahab, M. Misra, A.K. Mohanty, Epoxidized pine oil-siloxane: crosslinking kinetic study and thermomechanical properties, J. Appl. Polym. Sci. 132 (2015) 42451.

[27] G.S. Constable, A.J. Lesser, E.B. Coughlin, Morphological and mechanical evaluation of hybrid organic-inorganic thermoset copolymers of dicyclopentadiene and mono-or tris (norbornenyl)-substituted polyhedral oligomeric silsesquioxanes, Macromolecules 37 (2004) 1276-1282.

[28] G.X. Chen, L. Si, P. Lu, Q. Li, Epoxy hybrid composites cured with octaaminophenyl polyhedral oligomeric silsesquioxane, J. Appl. Polym. Sci.125 (2012) 3929-3935.

[29] B. Zhao, S. Xu, M. Adeel, S. Zheng, Formation of POSS $®-P O S S \bowtie$ interactions in polyurethanes: from synthesis, morphologies to shape memory properties of materials, Polymer 160 (2019) 82-92.

[30] W. Zhang, G. Camino, R. Yang, Polymer/polyhedral oligomeric silsesquioxane (POSS () nanocomposites: an overview of fire retardance, Prog. Polym. Sci. 67 (2017) $77-125$.

[31] G. Turgut, M. Dogan, U. Tayfun, G. Ozkoc, The effects of POSS $₫$ particles on the flame retardancy of intumescent polypropylene composites and the structureproperty relationship, Polym. Degrad, Stab 149 (2018) 96-111.

[32] X. Su, H. Xu, Y. Deng, J. Li, W. Zhang, P. Wang, Preparation and optical limiting

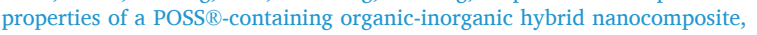
Mater. Lett. 62 (2008) 3818-3820.

[33] S.S. Ray, M. Okamoto, Polymer/layered silicate nanocomposites: a review from preparation to processing, Prog. Polym. Sci. 28 (2003) 1539-1641.

[34] D. Paul, L.M. Robeson, Polymer nanotechnology: nanocomposites, Polymer 49 (2008) 3187-3204.

[35] N.T. Dintcheva, E. Morici, R. Arrigo, F. La Mantia, V. Malatesta, J. Schwab, Structure-properties relationships of polyhedral oligomeric silsesquioxane (POSS () filled PS nanocomposites, Express Polym. Lett. 6 (2012) 561-571.

[36] A. Dantas, C.A.G. Beatrice, Polymer nanocomposites with different types of nanofiller, in: Subbarayan Sivasankaran (Ed.), Nanocomposites - Recent Evolutions, IntechOpen, 2018, https://doi.org/10.5772/intechopen.81329. Chapter 6, Intech.

[37] C. Zhang, X. Mi, J. Tian, J. Zhang, T. Xu, Supported ionic liquid silica as curing agent for epoxy composites with improved mechanical and thermal properties, Polymers 9 (2017) 478.

[38] M. Perchacz, R.K. Donato, L. Seixas, A. Zhigunov, R. Konefał, M. Serkis-Rodzeń, $\mathrm{H}$. Beneš, Ionic liquid-silica precursors via solvent-free sol-gel process and their application in epoxy-amine network: a theoretical/experimental study,, ACS Appl. Mater. Interfaces 9 (2017) 16474-16487.

[39] T.K. Ly Nguyen, M.M. Obadia, A. Serghei, S. Livi, J. Duchet-Rumeau, E. Drockenmuller, 1, 2, 3-triazolium-based epoxy-amine networks: ionconducting polymer electrolytes, macromol, Rapid Commun 37 (2016) 1168-1174.

[40] S. Livi, C. Chardin, L.C. Lins, N. Halawani, S. Pruvost, J. Duchet-Rumeau, J. F. Gérard, J.r.m. Baudoux, From ionic liquid epoxy monomer to tunable epoxy amine network: reaction mechanism and final properties, ACS, Sustain. Chem. Eng 7 (2019) 3602-3613.

[41] S. Livi, L.C. Lins, L.B. Capeletti, C. Chardin, N. Halawani, J. Baudoux, M. B. Cardoso, Antibacterial surface based on new epoxy-amine networks from ionic liquid monomers, Eur. Polym. J. 116 (2019) 56-64.

[42] P. Wasserscheid, T. Welton, Ionic Liquids in Synthesis, Second, Completely Revised and Enlarged Edition, Wiley-WCH Verlag GmbH \& Co, Weinheim, 2008. KGaA.

[43] A.E. Somers, P.C. Howlett, D.R. MacFarlane, M. Forsyth, A review of ionic liquid lubricants, Lubricants 1 (2013) 3-21.

[44] B.C. Ranu, S. Banerjee, Ionic liquid as catalyst and reaction medium. The dramatic influence of a task-specific ionic liquid, [bmIm] $\mathrm{OH}$, in michael addition of active methylene compounds to conjugated ketones, carboxylic esters, and nitriles, Org. Lett. 7 (2005) 3049-3052.

[45] A.V. Radchenko, J. Duchet-Rumeau, J.F. Gérard, J. Baudoux, S. Livi, Cycloaliphatic epoxidized ionic liquids as new versatile monomers for the development of shape memory PIL networks by 3D printing, Polym. Chem. 11 (2020) 5475-5483.

[46] N.V. Plechkova, K.R. Seddon, Applications of ionic liquids in the chemical industry, Chem. Soc. Rev. 37 (2008) 123-150.

[47] M. Leclère, S. Livi, M. Maréchal, L. Picard, J. Duchet-Rumeau, The properties of new epoxy networks swollen with ionic liquids,, RSC Adv. 6 (2016) 56193-56204.

[48] J. Le Bideau, L. Viau, A. Vioux, Ionogels, ionic liquid based hybrid materials, Chem. Soc. Rev. 40 (2011) 907-925.

[49] J. Dupont, R.F. de Souza, P.A. Suarez, Ionic liquid (molten salt) phase organometallic catalysis, Chem. Rev. 102 (2002) 3667-3692.

[50] C. Xing, J. Li, C. Yang, Y. Li, Local grafting of ionic liquid in poly (vinylidene fluoride) amorphous region and the subsequent microphase separation behavior in melt, Macromol. Rrapid Commun 37 (2016) 1559-1565.

[51] C. Xing, J. You, Y. Li, J. Li, Nanostructured poly (vinylidene fluoride)/ionic liquid composites: formation of organic conductive nanodomains in polymer matrix, J. Phys. Chem. C 119 (2015) 21155-21164.

[52] A.A. Silva, S. Livi, D.B. Netto, B.G. Soares, J. Duchet, J.F. Gérard, New epoxy systems based on ionic liquid, Polymer 54 (2013) 2123-2129.

[53] T. Shi, S. Livi, J. Duchet, J.F. Gérard, Ionic liquids-containing silica microcapsules: a potential tunable platform for shaping-up epoxy-based composite materials?,, Nanomaterials 10 (2020) 881. 
[54] H. Maka, T. Spychaj, R. Pilawka, Epoxy resin/ionic liquid systems: the influence of imidazolium cation size and anion type on reactivity and thermomechanical properties, Eng. Chem. Res. 51 (2012) 5197-5206.

[55] D. Shang, J. Fu, Q. Lu, L. Chen, J. Yin, X. Dong, Y. Xu, R. Jia, S. Yuan, Y. Chen, A novel polyhedral oligomeric silsesquioxane based ionic liquids (POSS $($-ILs) polymer electrolytes for lithium ion batteries, Solid State Ionics 319 (2018) $247-255$.

[56] F. Zhang, X. Bao, Q. Liu, M. Huang, High-temperature polymer electrolyte membranes based on poly (2, 5-benzimidazole)(ABPBI) and POSS $($ incorporated ionic liquid, J. Mater. Chem. Eng 2 (2014) 86-93.

[57] H. Chabane, S. Livi, H. Benes, C. Ladavière, P. Ecorchard, J. Duchet-Rumeau, J. F. Gérard, Polyhedral oligomeric silsesquioxane-supported ionic liquid for designing nanostructured hybrid organic-inorganic networks, Eur. Polym. J. 114 (2019) 332-337.

[58] A.V. Radchenko, H. Chabane, B. Demir, D.J. Searles, J. Duchet-Rumeau, J, F. Gerard, J. Baudoux, S. Livi, New epoxy thermosets derived from bisimidazolium ionic liquid monomer: an experimental and modelling investigation, ACS, Sustain. Chem. Eng 8 (2020) 12208-12221.

[59] A. Lesniewski, J. Niedziolka, B. Palys, C. Rizzi, L. Gaillon, M. Opallo, Electrode modified with ionic liquid covalently bonded to silicate matrix for accumulation of electroactive anions, Electrochem. Commun. 9 (2007) 2580-2584.

[60] C. Chardin, J. Rouden, S. Livi, J. Baudoux, 3-[2-(Oxiran-2-yl) ethyl]-1-\{4-[(2oxiran-2-yl) ethoxy] benzyl\} imidazolium bis (Trifluoromethane) sulfonimide, Molbank M974 (2018) 1-6.

[61] Y, g. Won, J. Galy, J. F. Gérard, J. P. Pascault, V. Bellenger, J. Verdu, Internal antiplasticization in copolymer and terpolymer networks based on diepoxides, diamines and monoamines, Polymer 31 (1990) 1787-1792.

[62] E. Mounif, V. Bellenger, P. Mazabraud, F. Nony, A. Tcharkhtchi, Chemorheological study of DGEBA/IPD system for reactive rotational molding (RRM), J. Appl. Polym. Sci. 116 (2010) 969-976.

[63] F.G. Garcia, B.G. Soares, V.J. Pita, R. Sánchez, J. Rieumont, Mechanical properties of epoxy networks based on DGEBA and aliphatic amines, J. Appl. Polym. Sci. 106 (2007) 2047-2055.

[64] D.K. Owens, R. Wendt, Estimation of the surface free energy of polymers, J. Appl. Polym. Sci. 13 (1969) 1741-1747.

[65] R.E. Lyon, R.N. Walters, Pyrolysis combustion flow calorimetry, J. Anal. Appl. Pyrolysis 71 (2004) 27-46.

[66] C. Huggett, Estimation of rate of heat release by means of oxygen consumption measurements, Fire Mater. 4 (1980) 61-65.

[67] W.D. Callister Jr., D.G. Rethwisch, Fundamentals of Materials Science and Engineering: an Integrated Approach, John Wiley \& Sons, 2012.

[68] R. Sonnier, A.S. Caro-Bretelle, L. Dumazert, M. Longerey, B. Otazaghine, Influence of radiation-crosslinking on flame retarded polymer materials-How crosslinking disrupts the barrier effect, Radiat. Phys. Chem.106 (2015) 278-288.

[69] Y.R. Ham, S.H. Kim, Y.J. Shin, D.H. Lee, M. Yang, J.H. Min, J.S. Shin, A comparison of some imidazoles in the curing of epoxy resin,, J. Ind. Eng. Chem. 16 (2010) 556-559.

[70] B.G. Soares, S. Livi, J. Duchet-Rumeau, J.F. Gérard, Synthesis and characterization of epoxy/MCDEA networks modified with imidazolium-based ionic liquids, Macromol. Mater. Eng. 296 (2011) 826-834.

[71] B.G. Soares, S. Livi, J. Duchet-Rumeau, J.F. Gerard, Preparation of epoxy/MCDEA networks modified with ionic liquids, Polymer 53 (2012) 60-66.

[72] M.A.M. Rahmathullah, A. Jeyarajasingam, B. Merritt, M. VanLandingham, S. H. McKnight, G.R. Palmese, Room temperature ionic liquids as thermally latent initiators for polymerization of epoxy resins, Macromolecules 42 (2009) 3219-3221.

[73] H. Weickmann, R. Delto, R. Thomann, R. Brenn, W. Döll, R. Mülhaupt, PMMA nanocomposites and gradient materials prepared by means of polysilsesquioxane

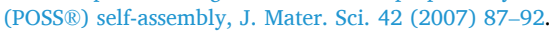

[74] Y. Ni, S. Zheng, K. Nie, Morphology and thermal properties of inorganic-organic hybrids involving epoxy resin and polyhedral oligomeric silsesquioxanes, Polymer 45 (2004) 5557-5568.

[75] Q. Wu, C. Zhang, R. Liang, B. Wang, Combustion and thermal properties of epoxy/phenyltrisilanol polyhedral oligomeric silsesquioxane nanocomposites, J. Therm. Anal. Calorim. 100 (2010) 1009-1015.

[76] H. Liu, S. Zheng, K. Nie, Morphology and thermomechanical properties of organic-inorganic hybrid composites involving epoxy resin and an incompletely condensed polyhedral oligomeric silsesquioxane, Macromolecules 38 (2005) 5088-5097.

[77] R. Donato, M. Perchacz, S. Ponyrko, K. Donato, H. Schrekker, H. Beneš, L. Matějka, Epoxy-silica nanocomposite interphase control using task-specific ionic liquids via hydrolytic and non-hydrolytic sol-gel processes, RSC Adv. 5 (2015) 91330-91339.

[78] Y. Deng, J. Bernard, P. Alcouffe, J. Galy, L. Dai, J.F. Gérard, Nanostructured hybrid polymer networks from in situ self-assembly of RAFT-synthesized POSSbased block copolymers, J. Polym. Sci., Polym. Chem. Ed. 49 (2011) 4343-4352.

[79] M. Mangion, G. Johari, Relaxations of thermosets. III. Sub-T dielectric relaxations of bisphenol-A-based epoxide cured with different cross-linking agents, J. Polym. Sci., Polym. Phys. Ed. 28 (1990) 71-83.
[80] B.X. Yang, K.P. Pramoda, G.Q. Xu, S.H. Goh, Mechanical reinforcement of polyethylene using polyethylene-grafted multiwalled carbon nanotubes, Adv. Funct. Mater. 17 (2007) 2062-2069.

[81] C.H. Tseng, C.C. Wang, C.Y. Chen, Functionalizing carbon nanotubes by plasma modification for the preparation of covalent-integrated epoxy composites, Chem. Mater. 19 (2007) 308-315.

[82] B.L. Silva, R.H. Bello, L.A. Ferreira Coelho, The role of the ratio (PEG: PPG) of a triblock copolymer (PPG-b-PEG-b-PPG) in the cure kinetics, miscibility and thermal and mechanical properties in an epoxy matrix, Polym, Bar Int. 67 (2018) 1248-1255.

[83] H. Abdollahi, A. Salimi, M. Barikani, A. Samadi, S. Hosseini Rad, A. Zanjanijam, Systematic investigation of mechanical properties and fracture toughness of epoxy networks: role of the polyetheramine structural parameters, J. Appl. Polym. Sci. 136 (2019) 47121.

[84] T.K.L. Nguyen, S. Livi, B.G. Soares, H. Benes, J.F. Gérard, J. Duchet-Rumeau, Toughening of epoxy/ionic liquid networks with thermoplastics based on poly (2, 6-dimethyl-1, 4-phenylene ether)(PPE), ACS Sustain. Chem. Eng. 5 (2017) $1153-1164$.

[85] T.K.L. Nguyen, B.G. Soares, J. Duchet-Rumeau, S. Livi, Dual functions of ILs in the core-shell particle reinforced epoxy networks: curing agent vs dispersion aids, Compos. Sci. Technol. 140 (2017) 30-38.

[86] Y. Haldorai, W.S. Lyoo, S.K. Noh, J.J. Shim, Ionic liquid mediated synthesis of silica/polystyrene core-shell composite nanospheres by radical dispersion polymerization, React. Funct. Polym. 70 (2010) 393-399.

[87] A. Kinloch, R. Mohammed, A. Taylor, C. Eger, S. Sprenger, D. Egan, The effect of silica nano particles and rubber particles on the toughness of multiphase thermosetting epoxy polymers, J. Mater. Sci. 40 (2005) 5083-5086.

[88] B. Johnsen, A. Kinloch, R. Mohammed, A. Taylor, S. Sprenger, Toughening mechanisms of nanoparticle-modified epoxy polymers, Polymer 48 (2007) 530-541.

[89] K. Aj, R. Young, Fracture Behavior of Polymers, App. Sci. Publishers, London, 1983.

[90] T.K.L. Nguyen, S. Livi, B.G. Soares, S. Pruvost, J. Duchet-Rumeau, J.F. Gérard, Ionic liquids: a new route for the design of epoxy networks,, ACS Sustain. Chem. Eng. 4 (2016) 481-490.

[91] K. Kim, J.D. Lichtenhan, J.U. Otaigbe, Facile route to nature inspired hydrophobic surface modification of phosphate glass using polyhedral oligomeric silsesquioxane with improved properties, Appl. Surf. Sci. 470 (2019) 733-743.

[92] J. Włoch, A.P. Terzyk, M. Wiśniewski, P. Kowalczyk, Nanoscale water contact angle on Polytetrafluoroethylene surfaces characterized by molecular DynamicsAtomic force microscopy imaging, Langmuir 34 (2018) 4526-4534.

[93] M. Kaur, G. Singh, S. Kumar, T.S. Kang, Thermally stable microemulsions comprising imidazolium based surface active ionic liquids, non-polar ionic liquid and ethylene glycol as polar phase, J. Colloid Interface Sci. 511 (2018) 344-354.

[94] S. Livi, A.A. Silva, J. Pereira, T.K.L. Nguyen, B.G. Soares, M.B. Cardoso, J. F. Gérard, J. Duchet-Rumeau, Supercritical $\mathrm{CO}_{2}$-organosilane mixtures for modification of silica: applications to epoxy prepolymer matrix, Chem. Eng. J. 241 (2014) 103-111.

[95] W. Peng, S. Xu, L. Li, C. Zhang, S. Zheng, Organic-inorganic nanocomposites via self-assembly of an amphiphilic triblock copolymer bearing a Poly (butadiene-gPOSS () subchain in epoxy thermosets: morphologies, surface hydrophobicity, and dielectric properties, J. Phys. Chem. B 120 (2016) 12003-12014.

[96] K. Zeng, S. Zheng, Nanostructures and surface dewettability of epoxy thermosets containing hepta $(3,3,3$-trifluoropropyl) polyhedral oligomeric silsesquioxanecapped poly (ethylene oxide), J. Phys. Chem. B 111 (2007) 13919-13928.

[97] L. Wang, S. Zheng, Surface morphology and dewettability of self-organized thermosets involving epoxy and POSS $®$-capped poly (ethylene oxide) telechelics, Mate, Chem. Phys. 136 (2012) 744-754.

[98] Q. Wu, C. Zhang, R. Liang, B. Wang, Combustion and thermal properties of epoxy/phenyltrisilanol polyhedral oligomeric silsesquioxane nanocomposites, J. Therm. Anal. Calorim. 100 (2009) 1009-1015.

[99] J. Sanes, N. Saurin, F. Carrion, G. Ojados, M. Bermudez, Synergy between singlewalled carbon nanotubes and ionic liquid in epoxy resin nanocomposites, Composites Part B: Engineering 105 (2016) 149-159.

[100] A. Ullah, S. Ullah, G.S. Khan, S.M. Shah, Z. Hussain, S. Muhammad, M. Siddiq, H. Hussain, Water soluble polyhedral oligomeric silsesquioxane based amphiphilic hybrid polymers: synthesis, self-assembly, and applications, Eur. Polym. J. 75 (2016) 67-92.

[101] R. Sonnier, B. Otazaghine, L. Dumazert, R. Ménard, A. Viretto, L. Dumas, L. Bonnaud, P. Dubois, N. Safronava, R. Walters, Prediction of thermosets flammability using a model based on group contributions, Polymer 127 (2017) 203-213.

[102] W. Zhang, X. Li, H. Fan, R. Yang, Study on mechanism of phosphorus-silicon synergistic flame retardancy on epoxy resins, Polym. Degrad. Stabil. 97 (2012) 2241-2248.

[103] G.M. Wu, B. Schartel, M. Kleemeier, A. Hartwig, Flammability of layered silicate epoxy nanocomposites combined with low-melting inorganic ceepree glass, Polym. Eng. Sci. 52 (2012) 507-517.

[104] G. Camino, G. Tartaglione, A. Frache, C. Manferti, G. Costa, Thermal and combustion behaviour of layered silicate-epoxy nanocomposites, Polym. Degrad. Stabil. 90 (2005) 354-362. 